\title{
Mixed Convection Stagnation Point Flow of the Blood Based Hybrid Nanofluid Around A Rotating Sphere
}

\section{Taza Gul ( $\square$ tazagul@cusit.edu.pk)}

City University of Science and Information Technology

\section{Basit Ali}

City University of Science and Information Technology

\section{Saleem Nasir}

City University of Science and Information Technology

\section{Muhammad Jawad}

Abdul Wali Khan University Mardan

Anwar Saeed

Abdul Wali Khan University Mardan

\section{Research Article}

Keywords: TiO2 and Ag nanoparticles, Human Blood, (OHAM), MHD, Rotating Sphere, Couple Stress.

Posted Date: December 30th, 2020

DOI: https://doi.org/10.21203/rs.3.rs-132540/v1

License: (9) This work is licensed under a Creative Commons Attribution 4.0 International License. Read Full License

Version of Record: A version of this preprint was published at Scientific Reports on April 2nd, 2021. See the published version at https://doi.org/10.1038/s41598-021-86868-x. 


\section{Mixed Convection Stagnation Point Flow of the Blood based Hybrid Nanofluid around a Rotating sphere}

Taza Gul ${ }^{1,2 *}$ Basit Ali $^{1}$, Saleem Nasir ${ }^{1}$, Muhammad Jawad ${ }^{3}$, Anwar Saeed ${ }^{3}$

${ }^{1}$ Department of Mathematics, City University of science and IT, Peshawar, 25000, KP, Pakistan.

${ }^{2}$ Higher education Department, Khyber Pakhtunkhwa, Peshawar, 25000, KP, Pakistan,

${ }^{3}$ Department of Mathematics, Abdul Wali Khan University, Mardan, 23200, KP, Pakistan.

${ }^{*}$ Corresponding author email: tazagul@ cusit.edu.pk.

\section{Abstract}

In this new world of fluid technologies, hybrid nanofluid has become a productive subject of research among scientists for its potential thermal features and abilities, which provides an excellent result as compared to nanofluids in growing the rate of heat transport. Our purpose here is to introduce the substantial influences of magnetic field on $2 \mathrm{D}$, time dependent and stagnation point inviscid flow of couple stress hybrid nanofluid around a rotating sphere with base fluid is pure blood, $\mathrm{TiO}_{2}$ and $\mathrm{Ag}$ as the nanoparticles. To translate the governing system of partial differential equations and the boundary conditions relevant for computation, some suitable transformations are implemented. To obtain the analytical estimations for the corresponding system of differential expression, the innovative Homotopy Analysis Method (HAM) approach is used. The characteristics of hybrid nanofluid flow patterns, including temperature, velocity and concentration profiles are simulated and analyzed in detail due to the variation in the evolving variables. A detailed research is also performed in order to investigate the influences of relevant constraints on the rates, momentum and heat transport for both $\mathrm{TiO}_{2}+\mathrm{Ag}+\mathrm{Blood}$ and $\mathrm{TiO}_{2}+\mathrm{Blood}$. One of the many outcomes of this analysis, it is observed that increasing the magnetic factor will decelerate the hybrid nanofluid flow velocity and improve the temperature profile. It may also be demonstrated that by increasing the Brownian motion factor, significant improvement can be made in the concentration field of hybrid nanofluid. The increase in the nanoparticle volume fraction from 0.01 to 0.02 in case of the hybrid nanofluid enhance the thermal conductivity from $5.8 \%$ to $11.947 \%$ and for the same value of the nanoparticle volume fraction in case of nanofluid enhance the thermal conductivity from $2.576 \%$ to $5.197 \%$.

Keywords, $\mathrm{TiO}_{2}$ and $\mathrm{Ag}$ nanoparticles; Human Blood; (OHAM); MHD; Rotating Sphere; Couple Stress.

\subsection{Introduction}

In recent studies, bio-nanotechnology is one of the revolutionary approaches that unlock the new frontiers in the field of biological science, medicine and engineering industries. This development involves the production and study of tiny materials supposed to be $1 \mathrm{~nm}$ to $100 \mathrm{~nm}$ in dimension. 
The main aim of the synthesis of nanomaterials and natural sciences is to introduce different novel nano-devices that allow revolutionary phenomena and biomedical discoveries to be explored at the molecular level. Such advancements provide science with a huge variety of techniques and instruments for clinical testing, medicinal and preventative healthcare applications. For that cause, an extension of certain nano-devices, nanomaterials including its implementations in biotechnology, drugs and engineering industries is explored by many other investigators [1-3]. In 1904 this was Maxwell [4] that specifically initiated the theory of retaining micro-scale particles in coolants, so it did not gain significant interest as a result of any drawbacks. Anyway, the theory once again captured the interest of researchers following the invention of nanoparticles. Choi [5] initially interpreted the expression Nanofluid. Sheikholeslami [6] simply stated, a nanofluid is just a liquid comprising tiny sized elements known as nanoparticles. In general, such nanoparticles are made of ceramic $\left(\mathrm{Al}_{2} \mathrm{O}_{3}, \mathrm{CuO}\right)$, metals $(\mathrm{Ag}, \mathrm{Cu}, \mathrm{Au})$, Ferro particles $\left(\mathrm{CoFe}_{2} \mathrm{O}_{4}, \mathrm{Fe}_{3} \mathrm{O}_{4}\right.$, $\mathrm{Mn}-\mathrm{ZnFe}_{2} \mathrm{O}_{4}$ ), metal nitrides $(\mathrm{AlN}, \mathrm{SiN})$, carbon in various forms (diamonds, graphite and carbon nanotubes) etc. Parvin and Chamkha [7] documented the heat transport, convection fluid flow and entropy generation in longitudinal and transverse enclosure form. $\mathrm{Cu} /$ water nanofluid occupies the space. Specifically, the quantitative simulation explains the influence of the fluid flow factors on Bejan and Nusselt numbers. A comprehensive analysis of Buongiorno nanofluid model for the solution of natural convectional flow in a partly warmed curly space fill by means of nanofluid has been performed by pop et al. [8]. Also, in another investigation Ghasemian et al. [9] examined the Buongiorno model to analyze the 3D uncontrolled movement of nanofluid through a square tube with sinusoidal diameter. In recent times, the concentration has been focused on the scientific research, analysis involving the saturation of two or even more nanomaterials in common fluid, termed hybrid nanofluid/ compound fluid [10].

A considerable majority of scholars have made some important attempts to investigate these types of hybrid nanofluid flows and many reports are available that casting the light on the possible features of those sorts of frameworks. In specific, nanofluid is quite recognized as high heat transport fluid. But, in this article the hybrid nanofluid is discussed to further improve the heat transport efficiency of the conventional nanofluid. Recently, various numerical studies were examined on hybrid nano fluids as a new idea in the field of science and technology. Devi and Devi [11] scrutinized the problems of heat transfer and flow of hydro-magnetic hybrid nano fluids $\left(\mathrm{Cu}-\mathrm{Al}_{2} \mathrm{O}_{3}\right.$ / water $)$ through an extending surface. Tayebi and Chamkha [12] computed numerically the problem of heat transport of hybrid nano fluids $\left(\mathrm{Cu}-\mathrm{Al}_{2} \mathrm{O}_{3} /\right.$ water $)$ in an annulus. In another investigation, the characteristics of $\mathrm{TiO}_{2}-\mathrm{Cu} / \mathrm{H}_{2} \mathrm{O}$ hybrid nano fluid with Lorentz force was scrutinized by Ghadikolaei et al. [13]. Hayat et al. [14] inspected the rotating flow problem of $\mathrm{Ag}-\mathrm{CuO} /$ water hybrid nano fluids. The aqueous Titania-copper hybrid nano fluid stagnation point flow towards stretching tube was explored by Yousefi et al. [15]. Subhani and Nadeem [16] studied the behavior of $\mathrm{Cu}-\mathrm{TiO}_{2} / \mathrm{H}_{2} \mathrm{O}$ (hybrid nano fluid) over the stretching surface. Dinarvand et al. [17] introduced $\mathrm{CuO}-\mathrm{Cu} /$ blood (hybrid nano fluid) circulation on a 
permeable stretching sheet, which is an advanced density concept, that can be a favorable model in the field of medical sciences, particularly in cancer therapy and drug delivery. In an investigation for cancer cell therapy, Liu et al. [18] examined that $\mathrm{Pt}-\mathrm{TiO}_{2}$ and $\mathrm{Au}-\mathrm{TiO}_{2}$ are the best nanocomposites. Through their laboratory analysis they found in the involvement of $\mathrm{TiO}_{2}$ or $\mathrm{Au}-\mathrm{TiO}_{2}$ nanoparticles, after two hours of treatment with UV irradiation the remaining fraction of cancer cell was diminished in both situations. In summary, this has been reported that most cancer cells will destroy using metal- $\mathrm{TiO}_{2}$ nanocomposite particles than $\mathrm{TiO}_{2}$ nanoparticles single which illustrates the need to use nano-materials in medicines. In combination with its special characteristics, $A g$ (silver) has various biomedical uses, such as permeability, strength, electrochemical and anti-bacterial properties. For anti-bacterial activities against the slew of micro-organisms such as microbes, protozoa, fungi, even the latest viruses, $A g$ and $A g$-related substances are used. Their contributions show the anti-tumor effect of $A g$ particles which indicate that they could be a cost-effective cancer therapy then another treatment [19].

In different engineering field, the fluid flowing around hot rotating frames has many implementations which include gravitational chemical processing, advanced technology, spin stabilized rocket temperature control, electric pumps and generators, thermal plasma manufacturing and painting spray processes. The self-similar approach for passing flow at the stagnation point through a spinning sphere in the presence of magnetic force influences have been investigated by Takhar and Nath [20]. In another work, Anilkumar and Roy [21] scrutinized time dependent variable viscosity movement in the zone of stagnation point a spinning sphere under which the free-stream momentum and angular speed of the revolving sphere varies gradually with time. The variational magnetic, thermal convectional flow via a spinning cone in transversely isotropic porous surface was investigated by Beg et al. [22]. Chamkha and Ahmad [23] calculated the numerical result of time dependent MHD free and mixed convectional motion and heat transport via a spinning sphere. More recently, Mahdy et al. [24] introduced a mathematical model to determine the Casson fluid flow of due to rotating sphere in the presence of conjugate MHD, entropy generation and convective boundary conditions.

Although, in our current model the base fluid is "pure blood", so it must be remembered that the blood viscidness is not really consistent from the medical perspective and it will be changed not only through vessel diameter, as well as by temperature, hematocrit factor and stress. In numerous investigations, this has been also specified that the presumption of Newtonian blood performance is suitable for high shear rate motion, for instance in the case of flow across blood vessels. Usually, as the human blood circulation improves, the blood thickness decreases, which can further improve the speed of blood flow and reduce clotting factors [25]. The curved flexible artery through which the viscosity of the blood is presumed to be temperature dependent was studied by Akbar and Nadeem [26]. The statistical blood flow model with circular based viscosity was examined by Gupta et al. [27]. Ijaz et al. [28] analyzed the theoretical results of hemodynamics with unique features utilizing $\mathrm{Cu}-\mathrm{CuO} / \mathrm{blood}$, hybrid nanofluid flow in stenosized arteries. Ellahi et al. [28] 
conducted a numerical investigation of the peristaltic flow of couple stress-based gold nanofluid among the hole of dual co-axial cylinders with various outlines and structure. Chahregh and Dinarvand [29] examined the circulation of $\mathrm{TiO}_{2}-\mathrm{Ag}$ /blood, hybrid nanofluid across a vessel for blood as well as drug transport applications in the respiration process.

Also, to the best of authors knowledge in the relevant literature, no one has ever tried to investigate the movement around a rotating sphere using pure blood as a based liquid and hybrid nanomaterials to explain many real-life applications of biomedical and medication filed and transportation. Supported by the said research findings, this article analyzes an appropriate framework of couple stress hybrid nanofluid movement of mixed convection across a spinning sphere in the immersion of MHD, thermophoresis and Brownian motion effect. The hybrid nanofluid is illustrated by maintaining two separate Titania $\left(\mathrm{TiO}_{2}\right)$ and silver $(\mathrm{Ag})$ nanoparticles in the base fluid blood. The governing equations including constraints are transformed into a boundary value problem of differential equations on the basis of the similarity transformation. Using the OHAM (Optimal Homotopy Asymptotic Method) in Mathematica, the system of equation system is then explained analytically. Moreover, the consequences on the characteristics of flow and heat transport of several other variables are seen numerically and graphically.

\subsection{Mathematical formulation}

In the stagnation point zone around a rotating sphere, we assume a time dependent flow of mixed convection of the couple stress hybrid nanofluid $\mathrm{TiO}_{2}-\mathrm{Ag}$ /blood with Buongiorno's mathematical model flow along with convective boundary conditions. Figure 1 demonstrates the working model and related coordinate structure of the problem. The working problem is presented on some specific assumptions:

i. The $\mathrm{x}$-axis is determined on the surface of a sphere and the y-axis is normal to it.

ii. The magnetic field $B(t)=B_{0} t^{\frac{-1}{2}}$ is considered perpendicular to the flow field.

iii. It is supposed that the temperature and concentration at the surface of the sphere have $T_{w}, C_{w}$ where $T_{\infty}, C_{\infty}$ the ambient temperature and concentration.

iv. The viscus dissipation terms are negligible.

v. Many mechanisms, including thermophoresis, Brownian motion and the MHD impacts are taken into consideration.

vi. The nanoparticles are supposed to be in thermal equilibrium.

In view of such flow assumptions, the resulting equations interpreted as:

$$
\frac{\partial(r u)}{\partial x}+\frac{\partial(r v)}{\partial y}=0
$$




$$
\begin{aligned}
& \frac{\partial u}{\partial t}+u \frac{\partial u}{\partial x}+v \frac{\partial u}{\partial y}-\left(\frac{w^{2}}{r}\right) \frac{d r}{d x}=\frac{\partial U}{\partial t}+U \frac{\partial U}{\partial x}+v_{h n f} \frac{\partial^{2} u}{\partial y^{2}}-\frac{\sigma_{h n f} B_{0}^{2}}{\rho_{h n f}}(u-U)-\frac{\eta_{0}}{\rho_{h n f}} \frac{\partial^{4} u}{\partial y^{4}} \\
& +\frac{g \beta^{*}\left(1-C_{\infty}\right) \rho_{f \infty}}{\rho_{h n f}} \times\left(T-T_{\infty}\right)-\frac{g\left(\rho_{p}-\rho_{f \infty}\right)}{\rho_{h n f}} \times\left(C-C_{\infty}\right) \\
& \frac{\partial w}{\partial t}+u \frac{\partial w}{\partial x}+v \frac{\partial w}{\partial y}+\left(\frac{w u}{r}\right) \frac{d r}{d x}=v_{h n f} \frac{\partial^{2} w}{\partial y^{2}}-\frac{\sigma_{h n f} B_{0}^{2} w}{\rho_{h n f}}-\frac{\eta_{0}}{\rho_{h n f}} \frac{\partial^{4} w}{\partial y^{4}} \\
& \frac{\partial T}{\partial t}+u \frac{\partial T}{\partial x}+v \frac{\partial T}{\partial y}=\alpha_{h n f} \frac{\partial^{2} T}{\partial y^{2}}+\tau\left(D_{B} \frac{\partial T}{\partial y} \frac{\partial C}{\partial y}+\frac{D_{T}}{T_{\infty}}\left(\frac{\partial T}{\partial y}\right)^{2}\right) \\
& \frac{\partial C}{\partial t}+u \frac{\partial C}{\partial x}+v \frac{\partial C}{\partial y}=D_{B} \frac{\partial^{2} C}{\partial y^{2}}+\frac{D_{T}}{T_{\infty}} \frac{\partial^{2} T}{\partial y^{2}} .
\end{aligned}
$$

In said expressions $\tau=\frac{\left(\rho c_{p}\right)_{h n f}}{\left(\rho c_{p}\right)_{f}}$ heat capacity ratio with $\left(\rho c_{p}\right)_{f}$ is the blood heat capacity, $\left(\rho c_{p}\right)_{h n f}$ is the solid nanoparticles heat capacity, $\left(D_{B}, D_{T}\right)$ are the diffusion coefficients of (Brownian, thermophoresis), $B_{0}$ is the magnetic field, $g$ is the gravitational acceleration, $u, v, w$ are velocities element in $x, y$ and $z$ directions, $\eta_{0}$ is the couple stress parameter, $\mu_{h n f}, \rho_{h n f}, \sigma_{\mathrm{hnf}}$ , $k_{h n f}$ and $\left(\rho C_{p}\right)_{h n f}$ are viscosity, density, electrical and thermal conductivities and specific heat, where hybrid nanofluid refer $h n f$. All such relations [11] and defined in Table 1 and 2.

Initially, as the first nanoparticle we scattered $\mathrm{TiO}_{2}$ (Titania) into the blood (base fluid) to produce a $\mathrm{TiO}_{2} /$ blood (mono-nano liquid). In our current $\mathrm{TiO}_{2} /$ blood (base liquid), $\mathrm{Ag}$ (Silver) is then dispersed as a supplementary nanoparticle to construct the appropriate $\mathrm{TiO}_{2}+\mathrm{Ag} /$ blood (hybrid nanofluid). In this case, the subscript $S_{1}$ denotes $\mathrm{TiO}_{2}$ (Titania nanoparticles), although subscript $S_{2}$ denotes to $A g$ (Silver nanoparticles) and subscript $f$ mentions pure blood (base fluid). In table 1,2, $\phi_{1}$ and $\phi_{2}$ are refer the volume fraction of $\mathrm{TiO}_{2}$ and $\mathrm{Ag}$ nanoparticles, where $\phi_{1}=\phi_{2}=0$ refer normal fluid.

\subsubsection{Initial and Boundary Conditions:}

Subject to the corresponding initial and boundary condition

$$
\begin{gathered}
\text { for } t<0, u(t, x, y)=0, v(t, x, y)=0, w(t, x, y)=0, T(t, x, y) \rightarrow T_{\infty}, C(t, x, y) \rightarrow C_{\infty} \\
y=0: u(t, x, y)=0, v(t, x, y)=0, w(t, x, y)=\Omega(t) r
\end{gathered}
$$




$$
\begin{aligned}
\text { for } t \geq 0:-\frac{k}{h}\left(\frac{\partial T}{\partial y}\right)=\left(T_{f}-T\right), \quad D\left(\frac{\partial C}{\partial y}\right)+\frac{D}{T_{\infty}}\left(\frac{\partial T}{\partial y}\right)=0, \\
u(t, x, \infty) \rightarrow 0, \quad U(t, x, \infty) \rightarrow 0, T(t, x, \infty) \rightarrow T_{\infty}, \quad C(t, x, \infty) \rightarrow C_{\infty} .
\end{aligned}
$$

\subsubsection{Similarity Variables:}

To renovate above expressions which represent the flow problem to dimensionless system, we use the following similarity transformation.

$$
\begin{aligned}
& \eta=\left(\frac{2}{v_{f} t}\right) y, u=\left(\frac{A x}{t}\right) F^{\prime}(\eta), U(t, x)=\frac{A x}{t}, w=\left(\frac{B x}{t}\right) G(\eta), \Omega(t)=\frac{B}{t} \\
& v=-\left(\frac{2 v_{f}}{t}\right) A F(\eta), \theta(\eta)=\frac{T-T_{\infty}}{T_{w}-T_{\infty}}, \phi(\eta)=\frac{C-C_{\infty}}{C_{w}-C_{\infty}}
\end{aligned}
$$

Invoking the similarity factors in Eq (7) in model Eq (1)- (5) with boundary condition Eq (1) converted into the following form:

$$
\begin{aligned}
& F^{\prime \prime \prime}+\left(1-\phi_{1}\right)^{2.5}\left(\left(1-\phi_{2}\right)^{2.5}\right)\left[\left(1-\phi_{2}\right)\left\{1-\left(1-\frac{\rho_{S_{1}}}{\rho_{f}}\right) \phi_{1}\right\}+\phi_{2} \frac{\rho_{S_{2}}}{\rho_{f}}\right] A\left[\begin{array}{l}
F F^{\prime \prime}-\frac{1}{2}\left(1-F-\frac{1}{2} \eta F^{\prime \prime}\right)+ \\
\frac{A}{2}\left(1-\left(F^{\prime}\right)^{2}+\lambda G^{2}\right)
\end{array}\right]+ \\
& \left(1-\phi_{1}\right)^{2.5}\left(1-\phi_{2}\right)^{2.5}\left[\frac{A}{2} \lambda^{*}(\theta-N r \Phi)-\frac{1}{2} M\left(F^{\prime}-1\right)\right]-k^{*} F^{v}=0 \\
& G^{\prime \prime}+\left(1-\phi_{1}\right)^{2.5}\left(\left(1-\phi_{2}\right)^{2.5}\right)\left[\left(1-\phi_{2}\right)\left\{1-\left(1-\frac{\rho_{S_{1}}}{\rho_{f}}\right)_{1}\right\}+\phi_{2} \frac{\rho_{S_{2}}}{\rho_{f}}\right]\left[A\left(F G^{\prime}-F^{\prime} G\right)+\frac{1}{2}\left(G+\frac{1}{2} \eta G^{\prime}\right)\right] \\
& -\frac{\left(1-\phi_{1}\right)^{2.5}\left(\left(1-\phi_{2}\right)^{2.5}\right)}{2} M G-k^{*} G^{i v}=0, \\
& \frac{k_{h n f}}{k_{f}} \theta^{\prime \prime}+\left[\left(1-\phi_{2}\right)\left\{1-\left(1-\frac{\left(\rho C_{p}\right)_{S_{1}}}{\left(\rho C_{p}\right)_{f}}\right) \phi_{1}\right\}+\phi_{2} \frac{\left(\rho C_{p}\right)_{S_{2}}}{\left(\rho C_{p}\right)_{f}}\right] \operatorname{Pr}\left(A F \theta^{\prime}+\frac{1}{4} \eta \theta^{\prime}+N_{b} \theta^{\prime} \Phi^{\prime}+N_{t}\left(\theta^{\prime}\right)^{2}\right)=0 \\
& \quad\left(1-\phi_{1}\right)\left(1-\phi_{2}\right) \Phi^{\prime \prime}+A S c f \Phi^{\prime}+\frac{1}{4} \eta S c \Phi+\frac{N_{t}}{N_{b}} \theta^{\prime \prime}=0 .
\end{aligned}
$$

Initial and boundary conditions in Eq. (6) transform into the following form 


$$
\begin{aligned}
& F(0)=F^{\prime}(0)=0, G(0)=1, \theta^{\prime}(0)=B i(\theta(0)-1), \\
& N_{b} \Phi^{\prime}(0)+N t \theta^{\prime}(0)=0, F^{\prime}(\infty) \rightarrow 1, G(\infty)=\theta(\infty)=\Phi(\infty) \rightarrow 0 .
\end{aligned}
$$

Here the Schmidt number, Prandtl number, Reynolds number, Grashof number, Couple stress parameter, Biot number, Buoyancy ratio, Brownian motion and thermophoresis parameters, the rotation parameter, mixed convection parameter and magnetic field parameter are

$$
\begin{aligned}
& S c=\frac{v_{f}}{D_{B}}, \operatorname{Pr}=\frac{\mu_{f} c_{p}}{k_{f}}, \operatorname{Re}=\frac{U x}{v_{f}}, k^{*}=\frac{2 \eta_{0}}{\rho_{f} v_{f}^{2}}, B_{i}=\frac{h}{k_{f}} \sqrt{\frac{v_{f}}{2}}, G r=\frac{g \beta^{*}\left(1-C_{\infty}\right)\left(T_{w}-T_{\infty}\right) \rho f_{\infty} x^{3}}{v_{f}^{2}}, \\
& N r=\frac{\left(\rho_{p}-\rho_{f}\right) C_{\infty}}{\rho f_{\infty} \beta^{*}\left(1-C_{\infty}\right)\left(T_{w}-T_{\infty}\right)}, N b=\tau \frac{D_{B} C_{\infty}}{v_{f}}, N t=\tau \frac{D_{T}\left(T_{w}-T_{\infty}\right)}{v_{f} T_{\infty}}, \lambda=\left(\frac{B}{A}\right)^{2}, \lambda^{*}=\frac{G r}{\operatorname{Re}^{2}}, M=\frac{\sigma B_{0}^{2}}{\rho_{f}} .
\end{aligned}
$$

\subsubsection{Skin friction and Nusselt number:}

$$
\begin{aligned}
\operatorname{Re}^{\frac{1}{2}} A^{\frac{1}{2}} C_{f x} & =\frac{2 \mu_{h n f}}{\rho_{f} U^{2}}\left(\frac{\partial u}{\partial y}\right)_{y=0}=\frac{2 \sqrt{2}}{\left(1-\phi_{1}\right)^{2.5}\left(1-\phi_{2}\right)^{2.5}} F^{\prime \prime}(0), \\
\operatorname{Re}^{\frac{1}{2}} A^{\frac{1}{2}} C_{f z} & =\frac{2 \mu_{h n f}}{\rho_{f} U^{2}}\left(\frac{\partial w}{\partial y}\right)_{y=0}=\frac{-2 \sqrt{2} \lambda}{\left(1-\phi_{1}\right)^{2.5}\left(1-\phi_{2}\right)^{2.5}} G^{\prime}(0), \\
\operatorname{Re}^{\frac{-1}{2}} A^{\frac{1}{2}} N u & =\frac{-k_{h n f}}{k_{f}\left(T_{w}-T_{\infty}\right)}\left(\frac{\partial T}{\partial y}\right)_{y=0}=\frac{-2 k_{h n f}}{k_{f}} \theta^{\prime}(0) .
\end{aligned}
$$

\subsection{Solution Methodology}

The newly introduced BVPh 2.0 package of HAM [31, 32] has been used to find the solution of the nonlinear problem. This package has the tendency to obtain the out puts of the modeled problem in short time. The recent solution has been achieved using the above mentioned package. The trail solution for the modeled problem is obtained as:

$$
\begin{aligned}
& F_{0}(\eta)=\eta-\eta e^{-\eta}, G_{0}(\eta)=e^{-\eta} \\
& \theta_{0}(\eta)=\frac{B_{i}}{1+B_{i}} e^{-\eta}, \Phi_{0}(\eta)=-\frac{N t}{N b}\left(\frac{B_{i}}{1+B_{i}}\right) e^{-\eta} .
\end{aligned}
$$

The square residual error for the each one equations (9-11) is obtained through:

$$
\begin{gathered}
\varepsilon_{k}^{F}\left(h_{F}, h_{\theta}, h_{\Phi}\right)=\frac{1}{L+1} \sum_{J=0}^{L}\left[\sum_{m=0}^{k}\left(F_{m}\right)_{\eta}=j \pi \eta, \sum_{m=0}^{k}\left(\theta_{m}\right)_{\eta}=j \pi \eta, \sum_{m=0}^{k}\left(\Phi_{m}\right)_{\eta}=j \pi \eta\right]^{2}, \\
\varepsilon_{k}^{G}\left(h_{F}, h_{G}\right)=\frac{1}{L+1} \sum_{J=0}^{L}\left[\sum_{m=0}^{k}\left(G_{m}\right)_{\eta}=j \pi \eta, \sum_{m=0}^{k}\left(F_{m}\right)_{\eta}=j \pi \eta\right]^{2},
\end{gathered}
$$




$$
\begin{gathered}
\varepsilon_{k}^{\theta}\left(h_{\theta}, h_{F}, h_{\Phi}\right)=\frac{1}{L+1} \sum_{J=0}^{L}\left[\sum_{m=0}^{k}\left(\theta_{m}\right)_{\eta}=j \pi \eta, \sum_{m=0}^{k}\left(F_{m}\right)_{\eta}=j \pi \eta, \sum_{m=0}^{k}\left(\Phi_{m}\right)_{\eta}=j \pi \eta\right]^{2}, \\
\varepsilon_{k}^{\Phi}\left(h_{\Phi}, h_{\theta}, h_{F}\right)=\frac{1}{L+1} \sum_{J=0}^{L}\left[\sum_{m=0}^{k}\left(\Phi_{m}\right)_{\eta}=j \pi \eta, \sum_{m=0}^{k}\left(F_{m}\right)_{\eta}=j \pi \eta, \sum_{m=0}^{k}\left(\theta_{m}\right)_{\eta}=j \pi \eta\right]^{2}, \\
\varepsilon^{t}=\varepsilon_{k}^{F}+\varepsilon_{k}^{G}+\varepsilon_{k}^{\theta}+\varepsilon_{k}^{\Phi} .
\end{gathered}
$$

The sum of the total residual errors $\varepsilon_{m}^{t}$ has been attained from the velocity, temperature and concentration profiles.

\subsection{Result and Discussion}

This portion of the current study is concentrated throughout the theoretical analysis of blood base hybrid nanofluid flow around a rotating sphere. From these analyses certain important insights are produced from the graphical configurations of the velocity, temperature and concentration profile, taking into account various groundbreaking parameters. In the presence of distinct nanoparticles, the whole theoretical analysis is based on comparing $\mathrm{TiO}_{2}$ /blood and $\mathrm{TiO}_{2}+\mathrm{Ag}$ /blood with the help of the stated problem. Through the aid of some fixed mathematical values of factors like $\phi_{1}=0.01-0.05$ (corresponds to $\mathrm{TiO}_{2}$ /blood case) and $\phi_{2}=0.01-0.05$ (corresponds to $\mathrm{TiO}_{2}+\mathrm{Ag}$ (bloodcase), $N_{r}=[-1,1], N_{b}=[0.2,1.2], N_{t}=[0.2,1.2], A=[0.1,0.8], S c=[0.4,4.0]$, $\lambda=[1.0,10.0], \lambda^{*}=[1.0,10.0]$ these configuration patterns are performed. In current analysis two different types of nanoparticles $\mathrm{TiO}_{2}$ /blood and $\mathrm{Ag} /$ blood are considered and its detail of thermophysical features of $\mathrm{TiO}_{2}$ /blood (nanofluid) and $\mathrm{TiO}_{2}+\mathrm{Ag} /$ blood (hybrid nanofluid) are presented in table 2 and 3. The thermal-physical characteristics of $\mathrm{TiO}_{2}, \mathrm{Ag}$ and blood at $25 \mathrm{C}^{0}$ are specified in Table 3. The comparison of the published with the present work is displayed in Table 4. Similarly, Table 5 displays the variation of both $\mathrm{C}_{f}$ for $\mathrm{TiO}_{2}$ /blood (nanofluid) and $\mathrm{TiO}_{2}+\mathrm{Ag}$ /blood (hybrid nanofluid). Since $C_{f}$ are directly related to $k^{*}, M,\left(\phi_{1}, \phi_{2}\right)$. As a consequence, it is dug out that the remarkable nature is investigated for $\mathrm{TiO}_{2} /$ blood (nanofluid) and $\mathrm{TiO}_{2}+\mathrm{Ag}$ /blood. In addition, it was clear from Table 5 that $\mathrm{C}_{f}$ in the case of $\mathrm{TiO}_{2}+\mathrm{Ag}$ /blood (hybrid nanofluid) demonstrated superiority when equated to the $\mathrm{TiO}_{2}$ /blood (nanofluid). The results of the current analysis for the $N u$ (heat transfer rate) are exposed in Table 6. It is worth mentioning that $N u$ is directly related to the $M, N_{t},\left(\phi_{1}, \phi_{2}\right)$. So $N u$ enhances due to the intensification of $M, N_{t},\left(\phi_{1}, \phi_{2}\right)$ parameters. The percentage (\%) enhancement in the heat transfer rate has been observed with the increment of the nanoparticle volume fractions $\phi_{1}, \phi_{2}$. Increase in the $\phi_{1}, \phi_{2}$ from 0.01 to 0.02 in case of the $\mathrm{TiO}_{2}+\mathrm{Ag}$ enhance the thermal conductivity $5.8 \%$ and 
$11.947 \%$ respectively. Furthermore, the same value of the nanoparticle volume fraction in case of $\mathrm{TiO}_{2}$ enhancing the thermal conductivity $2.576 \%$ and $5.197 \%$ respectively as shown in Table 6. Also, the convergence of OHAM-BVPh 2.0 package up to 25 orders of approximation is displayed in Table 7 and 8 for $\mathrm{TiO}_{2} /$ blood (nanofluid) and $\mathrm{TiO}_{2}+\mathrm{Ag} /$ blood (hybrid nanofluid) respectively.

Detailed results of the model problem have been achieved and its corresponding specifications are graphically presented for component of $F^{\prime}(\eta)$ and $G(\eta)$ ( primary and secondary velocities), $\theta(\eta)$ temperature field and $\Phi(\eta)$ nanoparticle concentration filed in Figs. 2-16.

Figs. 2-5, we have plotted to describe the physical behavior of $\mathrm{TiO}_{2} /$ blood and $\mathrm{TiO}_{2}+\mathrm{Ag} /$ blood on primary velocities $F^{\prime}(\eta)$ for variations in several variables present in the equation of motion. Such as $k^{*}, \phi_{1}, \phi_{2}, M$ and $\lambda^{*}$ on flow is investigated graphically. Figure 2 depicts a particular image of the $F^{\prime}(\eta)$ (primary velocity) profile for various values of $k^{*}$ (couple stress variable). It is predicted from the figure that $F^{\prime}(\eta)$ (primary velocity) for both cases of fluid ( $\mathrm{TiO}_{2} /$ blood and $\mathrm{TiO}_{2}+\mathrm{Ag} /$ blood $)$ declines as enhancing the value of $k^{*}$. The explanation is so clear. By strengthening $k^{*}$ variable slow down the motion of both fluid $\left(\mathrm{TiO}_{2} /\right.$ blood and $\mathrm{TiO}_{2}+\mathrm{Ag} /$ blood ) due to an increasing the drag force which is equal to an obvious reduction in the fluid viscosity. From such parabolic images, one should observe that the velocity of $\mathrm{TiO}_{2}+\mathrm{Ag} /$ blood case gives frequent decline relative to the case of $\mathrm{TiO}_{2} /$ blood nanofluid.

The influences of the first $\mathrm{TiO}_{2}$ and the second $\mathrm{Ag}$ nanoparticle volume fraction $\left(\phi_{1}, \phi_{2}\right)$ on the primary velocity field $F^{\prime}(\eta)$ is graphically presented in figure 3 . The primary velocity field $F^{\prime}(\eta)$ is clearly seen to be remarkably declined against the enhancing value of the nanoparticle volume fraction $\mathrm{TiO}_{2}$ and $\mathrm{Ag}\left(\phi_{1}, \phi_{2}\right)$ of fluids. Physically, the higher values of the nanoparticle volume fraction of $\mathrm{TiO}_{2} /$ blood and $\mathrm{TiO}_{2}+\mathrm{Ag} /$ blood causes the thinning behavior of the momentum boundary layer.

This should also be observed that the sharp decline in nanofluid $\mathrm{TiO}_{2}$ velocity is lower than that for hybrids nanofluid ( $\mathrm{TiO}_{2}+\mathrm{Ag} /$ blood $)$.

The effect of the $\mathrm{M}$ (magnetic parameter) on the $\mathrm{TiO}_{2}+\mathrm{Ag} /$ blood and $\mathrm{TiO}_{2}+\mathrm{Ag} /$ blood $\mathrm{F}^{\prime}(\eta)$ primary velocities is investigated and the fundamental physics is visually illustrated in figure 4 . Figure 4 indicates that when the $M$ (magnetic field) is raised, then the velocity field of $\mathrm{TiO}_{2} /$ blood and $\mathrm{TiO}_{2}+\mathrm{Ag} /$ blood fluid sluggish. This declining influence on the $F^{\prime}(\eta)$ velocity of the $\mathrm{TiO}_{2}+\mathrm{Ag} /$ blood is more prominent than $\mathrm{TiO}_{2} /$ blood. Such decline state of velocities happens owing to the production of resistant type force identified as Lorentz force. The strength 
of such force enhances with the rising strength of $M$ which counteracts the motion of fluid in boundary film and drop the viscosity of boundary film.

The effect of $\lambda^{*}$ (mixed convection parameters) on $\mathrm{TiO}_{2} /$ blood and $\mathrm{TiO}_{2}+\mathrm{Ag} /$ blood fluid of $F^{\prime}(\eta)$ primary velocity is demonstrated in Figure 5. In order to increase the $\lambda^{*}$ (mixed convection parameters) the $F^{\prime}(\eta)$ primary velocity is significantly accelerated. A $F^{\prime}(\eta)$ velocity enhancing is reported, through a greater magnitude of the $\lambda^{*}$ which could be due to the high buoyancy force. The supporting buoyancy force works as a desirable pressure gradient and significantly speeds up $F^{\prime}(\eta)$. This accelerating influence on $F^{\prime}(\eta)$ of the $\mathrm{TiO}_{2}+\mathrm{Ag}$ /blood is more prominent than that of the nanofluid.

Figs. 6-8, we have plotted to describe the physical behavior of $\mathrm{TiO}_{2} / \mathrm{blood}$ and $\mathrm{TiO}_{2}+\mathrm{Ag} / \mathrm{blood}$ on the secondary velocity $G(\eta)$ field for variations in several of model equations. The physical nature of these model factors $\phi_{1}, \phi_{2}, M$ and $\lambda$ on flow is graphically studied.

The influence of the $\mathrm{M}$ (magnetic field) on the both ( $\mathrm{TiO}_{2} /$ blood and $\mathrm{TiO}_{2}+\mathrm{Ag} / \mathrm{blood}$ ) nanofluid $G(\eta)$ secondary velocities is also examined and the essential physics is visually demonstrating in figure 6. Figure 6 specifies that when the magnitude of $M$ is more elevated than the $G(\eta)$ velocity field of $\mathrm{TiO}_{2} /$ blood and $\mathrm{TiO}_{2}+\mathrm{Ag} /$ blood fluid slow down. Such diminishing effect on the $G(\eta)$ of the $\mathrm{TiO}_{2}+\mathrm{Ag} /$ blood is much more prominent than the $\mathrm{TiO}_{2} /$ blood . Such decay condition of $G(\eta)$ velocities happens due to the creation of protected type force identified as Lorentz force. The power of such force improves with the growing strength of $M$ which offsets the speed of both fluids within boundary layer and drop the thickness of the boundary layer.

The $G(\eta)$ vs first $\mathrm{TiO}_{2}$ and second $\mathrm{Ag}$ nanoparticle volume fraction $\left(\phi_{1}, \phi_{2}\right)$ behaviors are seen in Figure 7, that indicates that $\mathrm{G}(\eta)$ of both $\left(\mathrm{TiO}_{2} /\right.$ blood and $\left.\mathrm{TiO}_{2}+\mathrm{Ag} / \mathrm{blood}\right)$ decreases as the $\left(\phi_{1}, \phi_{2}\right)$ increases. Substantially, the higher values of both $\left(\phi_{1}, \phi_{2}\right)$ of nanofluid and hybrid nanofluid cause the thinning behavior of the momentum boundary layer. This should also be observed that the sharp decline in nanofluid $\mathrm{TiO}_{2}$ velocity is lower than that for hybrids nanofluid ( $\mathrm{TiO}_{2}+\mathrm{Ag} /$ blood).

The effect of the $\lambda$ (rotation parameter) of $\mathrm{TiO}_{2} /$ blood and $\mathrm{TiO}_{2}+\mathrm{Ag} /$ blood fluid on $\mathrm{G}(\eta)$ secondary velocity components is seen in Figure 8. In order to upsurge the magnitude of $\lambda$, the $G(\eta)$ secondary velocity components are significantly accelerated. It is clear from the diagram that the rotation becomes much more intense by increasing the $\lambda$, and the $G(\eta)$ secondary momentum helps more through the swirl effect that retards the secondary movement $G(\eta)$. 
From this parabolic plot, one should perceive that the velocity of $\mathrm{TiO}_{2}+\mathrm{Ag} /$ blood case gives frequent increase relative to the case of $\mathrm{TiO}_{2} /$ blood nanofluid.

The Figures 9-13, afterward demonstrating the effect of $\operatorname{Pr}, M, A,\left(\phi_{1}, \phi_{2}\right)$ and $N_{t}$ on $\theta(\eta)$ for both ( $\mathrm{TiO}_{2} /$ blood and $\mathrm{TiO}_{2}+\mathrm{Ag} / \mathrm{blood}$ ). To scrutinize the trend of Pr on $\theta(\eta)$, Figure 9 is plotted for both cases of ( $\mathrm{TiO}_{2} /$ blood and $\left.\mathrm{TiO}_{2}+\mathrm{Ag} / \mathrm{blood}\right)$. It is evident from the plot that the $\theta(\eta)$ field shows the diminishing role for $\operatorname{Pr}$. Consequently, it is defensible owing to the basic reason that thermal conductivity of the fluid relative lesser with an intensified magnitude of Prand thus reducing the temperature of both $\left(\mathrm{TiO}_{2} /\right.$ blood and $\mathrm{TiO}_{2}+\mathrm{Ag} /$ blood $)$. It's also reported herein that in the scenario of $\mathrm{TiO}_{2}+\mathrm{Ag} /$ blood the $\theta(\eta)$ temperature field reached its maximum value as compared to the $\mathrm{TiO}_{2} /$ blood nanofluid case.

The variance in $M$ (magnetic parameter) on temperature $\theta(\eta)$ profile is depicted in figure 10 for both ( $\mathrm{TiO}_{2} /$ blood and $\mathrm{TiO}_{2}+\mathrm{Ag} /$ blood). Form this drawing it is detected that $\theta(\eta)$ and thermal layer thickness enhances via growing magnitude of magnetic parameter $M$. The magnetic parameter and density of $\left(\mathrm{TiO}_{2} /\right.$ blood and $\mathrm{TiO}_{2}+\mathrm{Ag} /$ blood $)$ are inversely related with each other. Hence, the strengthening value of $M$ shrinking the density and as a consequence the thermal nature of fluid upsurges. From this outline, one can observe that the temperature for $\mathrm{TiO}_{2}+\mathrm{Ag} /$ blood case tends to decrease more quickly relative to the case of $\mathrm{TiO}_{2} /$ blood .

The effect of the $A$ (unsteadiness parameter) on both $\left(\mathrm{TiO}_{2} /\right.$ blood and $\left.\mathrm{TiO}_{2}+\mathrm{Ag} / \mathrm{blood}\right), \theta(\eta)$ temperature profiles is revealed in Figures 11. This can be seen from a plot that are rising the magnitude of $A$ leads to a reduction in the temperature field. Physically, with increasing values of $A$, the $\theta(\eta)$ field is reduced, indicating that the thermal boundary surfaces are diminished with the growing magnitude of $A$. Therefore, the boundary layer is cooler, so additional temperature and nanoparticles are moved to the surface of the sphere (wall) with a growing magnitude of $A$. It's also described herein that in the scenario of $\mathrm{TiO}_{2}+\mathrm{Ag} /$ blood the $\theta(\eta)$ temperature field reached its maximum value as compared to the $\mathrm{TiO}_{2} /$ blood nanofluid case.

The effect of $\left(\phi_{1}, \phi_{2}\right)$ on $\theta(\eta)$ is also studied and the basic reason is obviously portrayed in figure 12 . From the drawing it is observed that the $\theta(\eta)$ is enhanced for the increase in the volume concentration of both nanoparticles $\mathrm{TiO}_{2} /$ blood and hybrid $\mathrm{TiO}_{2}+\mathrm{Ag} /$ blood, which can be attributed to the collisions between the suspended $\mathrm{TiO}_{2}, \mathrm{Ag}$ nanoparticles. $\left(\phi_{1}, \phi_{2}\right)$ is basically link to both $\mathrm{TiO}_{2}, \mathrm{Ag}$ nanoparticles, therefore, the effect of both nanoparticles on $\theta(\eta)$ is observed. Mostly, the stimulation of thermal boundary film viscosity to $\left(\phi_{1}, \phi_{2}\right)$ is linked to upgraded thermal conduction of both $\left(\mathrm{TiO}_{2} /\right.$ blood and $\mathrm{TiO}_{2}+\mathrm{Ag} /$ blood $)$. In fact, superior amount of thermal 
conduction is reinforced by improved thermal diffusivity. Actually, $\theta(\eta)$ field is directly related to both $\left(\phi_{1}, \phi_{2}\right)$ in case of contraction and in this scenario, it displays extra inconsistency closed to the wall of the sphere.

Due to evolving $N_{t}$ (thermophoresis parameter), this paragraph is dedicated to capturing the variation in the $\theta(\eta)$ temperature profile for both nanoparticles $\mathrm{TiO}_{2} /$ blood and hybrid $\mathrm{TiO}_{2}+\mathrm{Ag} /$ blood. Figure 11 is depicted in order to observe the way that $\theta(\eta)$ temperature is affected. Figure 13 illustrates that the magnitude of both $\left(\mathrm{TiO}_{2} /\right.$ blood and $\left.\mathrm{TiO}_{2}+\mathrm{Ag} / \mathrm{blood}\right)$ temperature grows by enhancing $N_{t}$. Basically, it is how the thermophoresis force allows the particles to shift from the hot zone to the cold area, improves as $N_{t}$ raises and the thermophoresis force improves which upgrades the magnitude of $\theta(\eta)$ temperature field magnitude of nanofluids $\mathrm{TiO}_{2}$ / blood and hybrid nanofluids $\mathrm{TiO}_{2}+\mathrm{Ag}$ / blood .

Figures 14-16, we have designed to define the physical characteristics of $\mathrm{TiO}_{2} /$ blood and $\mathrm{TiO}_{2}+\mathrm{Ag}$ /blood on concentration profile $\Phi(\eta)$ for variations in several variable present in the model equations. Such as $S c,\left(\phi_{1}, \phi_{2}\right)$ and $N_{b}$ on concentration profile $\Phi(\eta)$ is investigated graphically.

The consequence of the $S c$ (Schmidt Number) on $\Phi(\eta)$ (concentration) profiles is portrayed in figure 14 for the case of $\left(\mathrm{TiO}_{2} /\right.$ blood and $\mathrm{TiO}_{2}+\mathrm{Ag} /$ blood $)$. The $\Phi(\eta)$ magnitude is reduced slightly substantially with rising values of $S c$. Basically, the relation of momentum diffusivity to mass (nanoparticle) diffusivity is called $S c$. For $S c<1$, diffusivity in mass dominates diffusivity in momentum, and vice versa for $S c>1$. Hence, with higher $S c$, concentration boundary-layer density for both nanoparticles $\mathrm{TiO}_{2}, \mathrm{Ag}$ is substantially enhanced, while the thermal boundarylayer density is marginally reduced.

In order to see the influence of volumetric fractions of nanomaterials $\left(\phi_{1}, \phi_{2}\right)$ on the concentration profile $\Phi(\eta)$, figure 15 has been plotted for both ( $\mathrm{TiO}_{2} /$ blood and $\left.\mathrm{TiO}_{2}+\mathrm{Ag} / \mathrm{blood}\right)$. It is noticeable that the decline in solute concentration was perceived by growing the volumetric fraction of nano additives $\left(\phi_{1}, \phi_{2}\right)$. In addition, lower values for $\mathrm{TiO}_{2}+\mathrm{Ag} / \mathrm{blood}$, hybrid nanofluid were observed in the $\Phi(\eta)$ profile when equated to $\mathrm{TiO}_{2}$ / blood nanofluid.

The effect of the $\Phi(\eta)$ concentration profile of the $N_{b}$ (Brownian motion parameter) is displayed in Figure 16 for the case of $\left(\mathrm{TiO}_{2} /\right.$ blood and $\left.\mathrm{TiO}_{2}+\mathrm{Ag} / \mathrm{blood}\right)$. An improvement to $\mathrm{N}_{b}$ lead to accelerates $\Phi(\eta)$ as seen in Figure. Physically, it is attributable to disperse through the $\left(\mathrm{TiO}_{2}, \mathrm{Ag}\right.$ ) particles, fluid improvements with the maximization of $N_{b}$. It is therefore understood that in the 
case of $\mathrm{TiO}_{2}+\mathrm{Ag}$ /blood, hybrid nanofluid, as can be seen in the figure the temperature gets its highest values as compared with $\mathrm{TiO}_{2} /$ blood nanofluid.

\subsection{Concluding Remarks}

The circulation of the $\mathrm{TiO}_{2}+\mathrm{Ag}$ /blood, hybrid nanofluid was examined around a rotating sphere under the action of a uniform applied magnetic field. The velocity, temperature along with concentration distribution, was also scientifically and systematically analyzed by taking the effects of $N_{b}, N_{t}$ and $\left(\phi_{1}, \phi_{2}\right)$ into consideration. The main results of this analysis were the following:

The $F^{\prime}(\eta)$ component of primary velocity, declined with the boosting value of $\left(\phi_{1}, \phi_{2}\right)$ and $M$, while an accelerating behavior was perceived via enhancing value of $\lambda^{*}$.

Also, the $G(\eta)$ secondary velocity component, boosted with the enhancing value of $\lambda$, where declinatory conduct was found through increasing values of $\left(\phi_{1}, \phi_{2}\right)$ and $M$. In contrast to $\mathrm{TiO}_{2}$ nanofluid, the $\mathrm{TiO}_{2}+\mathrm{Ag}$ /blood (hybrid nanofluid) demonstrated a weak velocity profile of $F^{\prime}(\eta)$ and $G(\eta)$.

For the growing values of $\left(\phi_{1}, \phi_{2}\right), N_{t}$ and $M$, temperature elevation was chronicled. In those scenarios, the $\mathrm{TiO}_{2}+\mathrm{Ag}$ /blood (hybrid nanofluid) exhibited the greatest temperature as equated to $\mathrm{TiO}_{2}$ nanofluid.

With the increasing value of $N_{b}$, an increase in the $\Phi(\eta)$ was observed. However, an opposite pattern was reported in increasing $\left(\phi_{1}, \phi_{2}\right)$ and $S c$.

$\mathrm{Nu}$ and $\mathrm{C}_{f}$ demonstrated considerable superiority in the case of $\mathrm{TiO}_{2}+\mathrm{Ag}$ /blood (hybrid nanofluid) as equated to $\mathrm{TiO}_{2}$ nanofluid.

There was considerable realistic relevance to the current study, particularly in the field of biomedical and chemical industries.

The output shows that the increase in the $\phi_{1}, \phi_{2}$ from 0.01 to 0.02 in case of the $\mathrm{TiO}_{2}+\mathrm{Ag}$ enhance the thermal conductivity $5.8 \%$ and $11.947 \%$ and for the same value of the nanoparticle volume fraction in case of $\mathrm{TiO}_{2}$ enhancing the thermal conductivity $2.576 \%$ and $5.197 \%$.

Conflict of interest: The authors do not have any conflict of interest.

\section{REFERENCES}

[1]. Bhatti, M.M., Zeeshan, A., Ellahi, R. Endoscope analysis on peristaltic blood flow of Sisko fluid with titanium magneto-nanoparticles, Comput. Biol. Med. 78 (2016) 29-41.

[2]. Ijaz, S., Nadeem, S. A biomedical solicitation examination of nanoparticles as drug agent to minimize the hemodynamics of stenotic channel, Eur. Phys. J. Plus 132 (2017) 448. 
[3]. Kamyar, A., Saidur, R., Hasanuzzaman, M. Application of computational fluid dynamics (CFD) for nanofluids, Int. J. Heat Mass Transfer 55 (15-16) (2012) 4104-4115.

[4]. Maxwell, J.C. (1904), Electricity and Magnetism, 3rd ed., Oxford, Oxford.

[5]. Choi, S. U., \& Eastman, J. A. (1995). Enhancing thermal conductivity of fluids with nanoparticles (No. ANL/MSD/CP-84938, CONF-951135-29). Argonne National Lab., IL (United States).

[6]. Sheikholeslami, M., Öztop, H.F., Abu-Hamdeh, N. and Li, Z. Nanoparticle transportation of $\mathrm{CuO}-\mathrm{H} 2 \mathrm{O}$ nanofluid in a porous semi annulus due to lorentz forces, Int. J. of Num. Methods for Heat and Fluid Flow, 2019, 29(1), 294-308.

[7]. Parvin, S. and Chamkha, A.J. An analysis on free convection flow, heat transfer and entropy generation in an odd-shaped cavity filled with nanofluid, Int. Commun. in Heat and Mass Transfer, 2014, 54, 8-17.

[8]. Pop, I., Sheremet, M. and Cimpean, D.S. Natural convection in a partially heated wavy cavity filled with a nanofluid using Buongiorno's nanofluid model, Int. J. of Num. Methods for Heat and Fluid Flow, 2017, 27(4), 924-940.

[9]. Ghasemian, A., Dinarvand, S., Adamian, A. and Sheremet, M.A. Unsteady general threedimensional stagnation point flow of a maxwell/Buongiorno non-Newtonian nanofluid, J. of Nanofluids, 2019, 8(7), 1544-1559.

[10]. Ijaz, S. and Nadeem, S. Biomedical theoretical investigation of blood mediated nanoparticles (Ag-Al2O3/blood) impact on hemodynamics of overlapped stenotic artery, J. of Mol. Liq., 2017, 248, 809-821.

[11]. Devi, S. A., \& Devi, S. S. U. Numerical investigation of hydromagnetic hybrid $\mathrm{Cu}-\mathrm{Al} 2 \mathrm{O} 3 /$ water nanofluid flow over a permeable stretching sheet with suction. Int. J. of Nonlinear Sci. and Num. Sim., 2016, 17(5), 249-257.

[12]. Tayebi, T., \& Chamkha, A. J. Free convection enhancement in an annulus between horizontal confocal elliptical cylinders using hybrid nanofluids. Numerical Heat Transfer, Part A: Applications, 2016, 70(10), 1141-1156.

[13]. Ghadikolaei, S. S., Yassari, M., Sadeghi, H., Hosseinzadeh, K., \& Ganji, D. D. Investigation on thermophysical properties of Tio2- $\mathrm{Cu} / \mathrm{H} 2 \mathrm{O}$ hybrid nanofluid transport dependent on shape factor in MHD stagnation point flow, Powder technology, 2017, 322, 428-438.

[14]. Hayat, T., Nadeem, S., \& Khan, A. U. Rotating flow of Ag-CuO/H 2 O hybrid nanofluid with radiation and partial slip boundary effects. The European Phys. J. E, 2018, 41(6), 75-87.

[15]. Yousefi, M., Dinarvand, S., Yazdi, M. E., \& Pop, I. Stagnation-point flow of an aqueous titaniacopper hybrid nanofluid toward a wavy cylinder, Int. J. of Numerical Methods for Heat \& Fluid Flow, 2018, 28(7), 1716-1735

[16]. Subhani, M., Nadeem, S. Numerical analysis of micropolar hybrid nanofluid, App. Nano-sci. 2019, 9(4), 447-459.

[17]. Dinarvand, S., Nademi Rostami, M., Dinarvand, R. and Pop, I. Improvement of drug delivery micro-circulatory system with a novel pattern of $\mathrm{CuO}-\mathrm{Cu} /$ blood hybrid nanofluid flow towards a porous stretching sheet, International Journal of Numerical Methods for Heat and Fluid Flow, 2019, 29(11), 4408-4429

[18]. Liu, L., Miao, P., Xu, Y., Tian, Z., Zou, Z. and Li, G. Study of Pt/TiO2 nanocomposite for cancer cell treatment, J. of Photochemistry and Photobiology B: Biology, 2010, 98(3), 207-210. 
[19]. Sriram, M.I., Kanth, S.B., Kalishwaralal, K. and Gurunathan, S. Antitumor activity of silver nanoparticles in dalton's lymphoma ascites tumor model, Int. Journal of Nanomedicine, 2010, 5, 753-762.

[20]. Takhar,H. S., and Nath, G., Self-Similar Solution of the Unsteady Flow in the Stagnation Point Region of a Rotating Sphere with a Magnetic Field," Heat and Mass Transfer, 2000, 36(2), 8996.

[21]. Anilkumar, D., and Roy, S., Self-Similar Solution of the Unsteady Mixed Convection Flow in the Stagnation Point Region of a Rotating Sphere, Heat and Mass Transfer, 2004, 40(6-7), 487493.

[22]. Bég, O. A., Prasad, V. R., Vasu, B., and Gorla, R. S. R., Computational Modeling of Magnetohydrodynamic Convection from a Rotating Cone in Orthotropic Darcian Porous Media, Journal of the Brazilian Society of Mechanical Sciences and Engineering, 2017, 39(6), 20352054.

[23]. Chamkha, A. J., and Ahmed, S. E., Unsteady MHD Heat and Mass Transfer by Mixed Convection Flow in the Forward Stagnation Region of a Rotating Sphere at Different Wall Conditions, Chemical Engineering Communications, 2012, 199(1), 122-141.

[24]. Mahdy, A., Chamkha, A. J., Nabwey, H.A. Entropy analysis and unsteady MHD mixed convection stagnation-point flow of Casson nanofluid around a rotating sphere, Alexandria Engineering Journal, 2020, 1-11, https://doi.org/10.1016/j.aej.2020.04.028

[25]. Cinar, Y., Kosku, N. Hypothesis: temperature stress and blood viscosity affects the leukocyte flexibility, coagulation, intracranial hypertension, and hemodynamics, 3. International Conference on Life Science and Technology, IACSIT Press. 2011, 120-126.

[26]. Akbar, N.S., Nadeem, S. Simulation of variable viscosity and Jeffrey fluid model for blood flow through a tapered artery with a stenosis, Commun. Theor. Phys. 2012, 57, 133-140.

[27]. Gupta, S., Gupta, M., Singh, S.P. Effect of radial viscosity variation on non- Newtonian flow of blood in a stenosed artery, Int. J. of Appl. Math and Mech. 2012, 8, 51-61.

[28]. Ijaz, S., Iqbal, Z., Maraj, E.N., Nadeem, S. Investigation of $\mathrm{Cu}-\mathrm{CuO} / \mathrm{blood}$ mediated transportation in stenosed artery with unique features for theoretical outcomes of hemodynamics, Journal of Molecular Liquids, 2018, 254, 421-432.

[29]. Chahregh, H. S., Dinarvand, S. TiO2-Ag/blood hybrid nanofluid flow through an artery with applications of drug delivery and blood circulation in the respiratory system, International Journal of Numerical Methods for Heat \& Fluid Flow, 2020, 1-22, DOI 10.1108/HFF-10-2019-0732

[30]. Ellahi, R., Zeeshan, A., Hussain, F., Asadollahi, A. Peristaltic Blood Flow of Couple Stress Fluid Suspended with Nanoparticles under the Influence of Chemical Reaction and Activation Energy, Symmetry, 2019, 11(2), 1-17.

[31]. Liao, SJ. An optimal homotopy-analysis approach for strongly nonlinear differential equations, Commun Nonlinear Sci Numer Simul, 2010, 15, 2003-2016.

[32]. Gul, T., Kiran, F. The experimental study to examine the stable dispersion of the graphene nanoparticles and to look at the GO-H2O nanofluid flow between two rotating disks, Applied Nanoscience, 2018, 8, 1711-1727. 
Figures

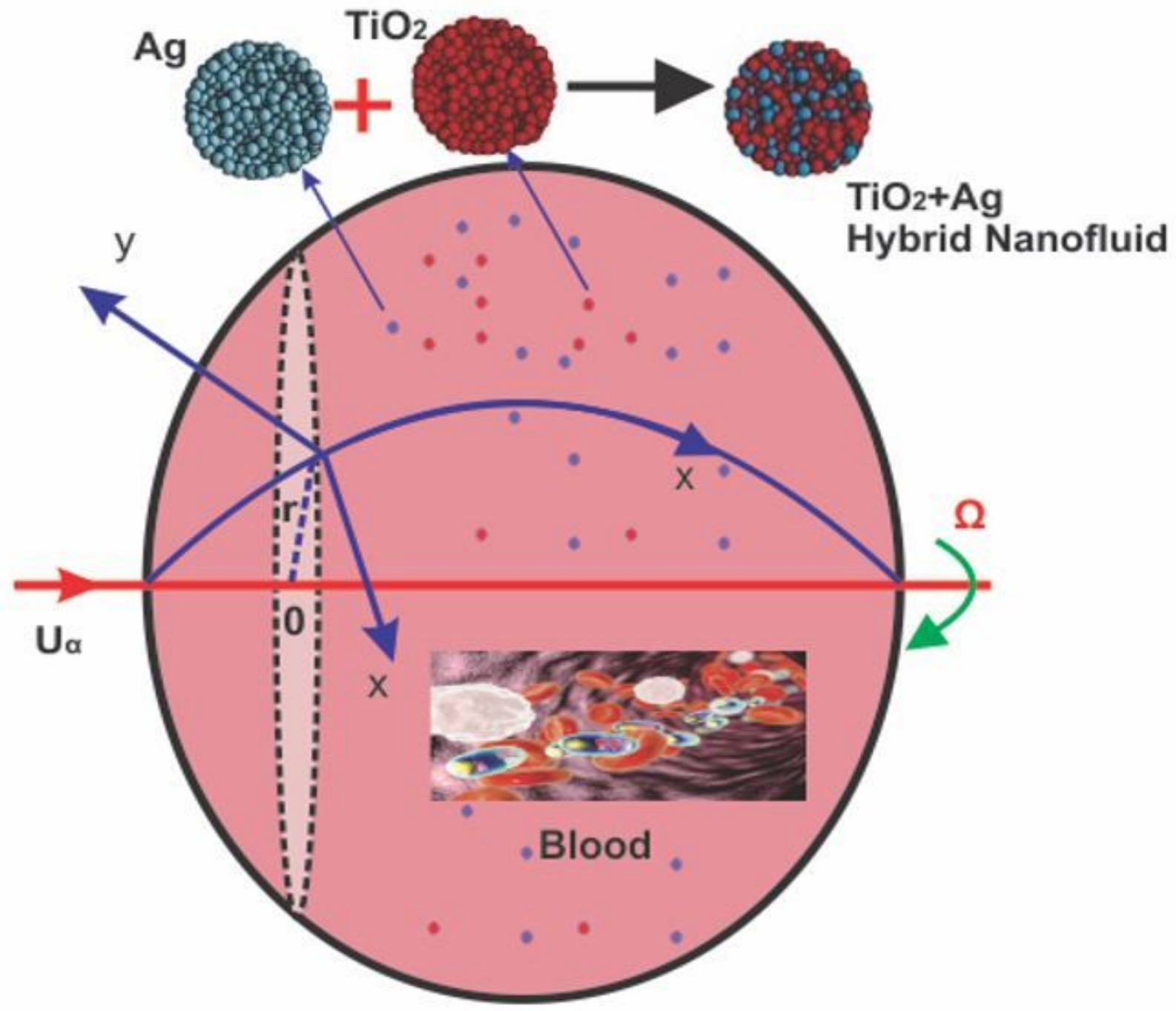

Figure 1

"See the Supplemental Files section for the complete figure caption". 


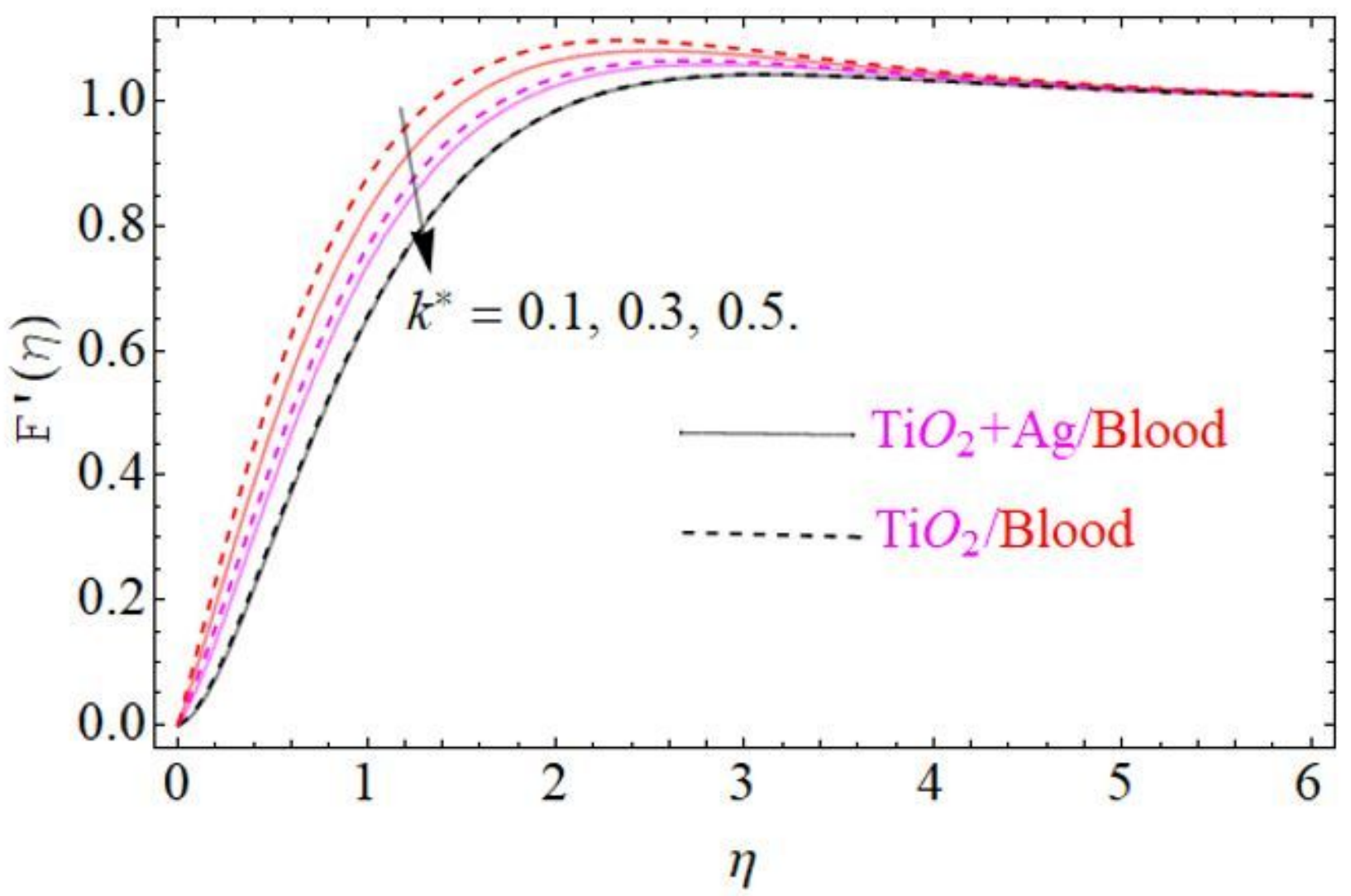

Figure 2

"See the Supplemental Files section for the complete figure caption". 


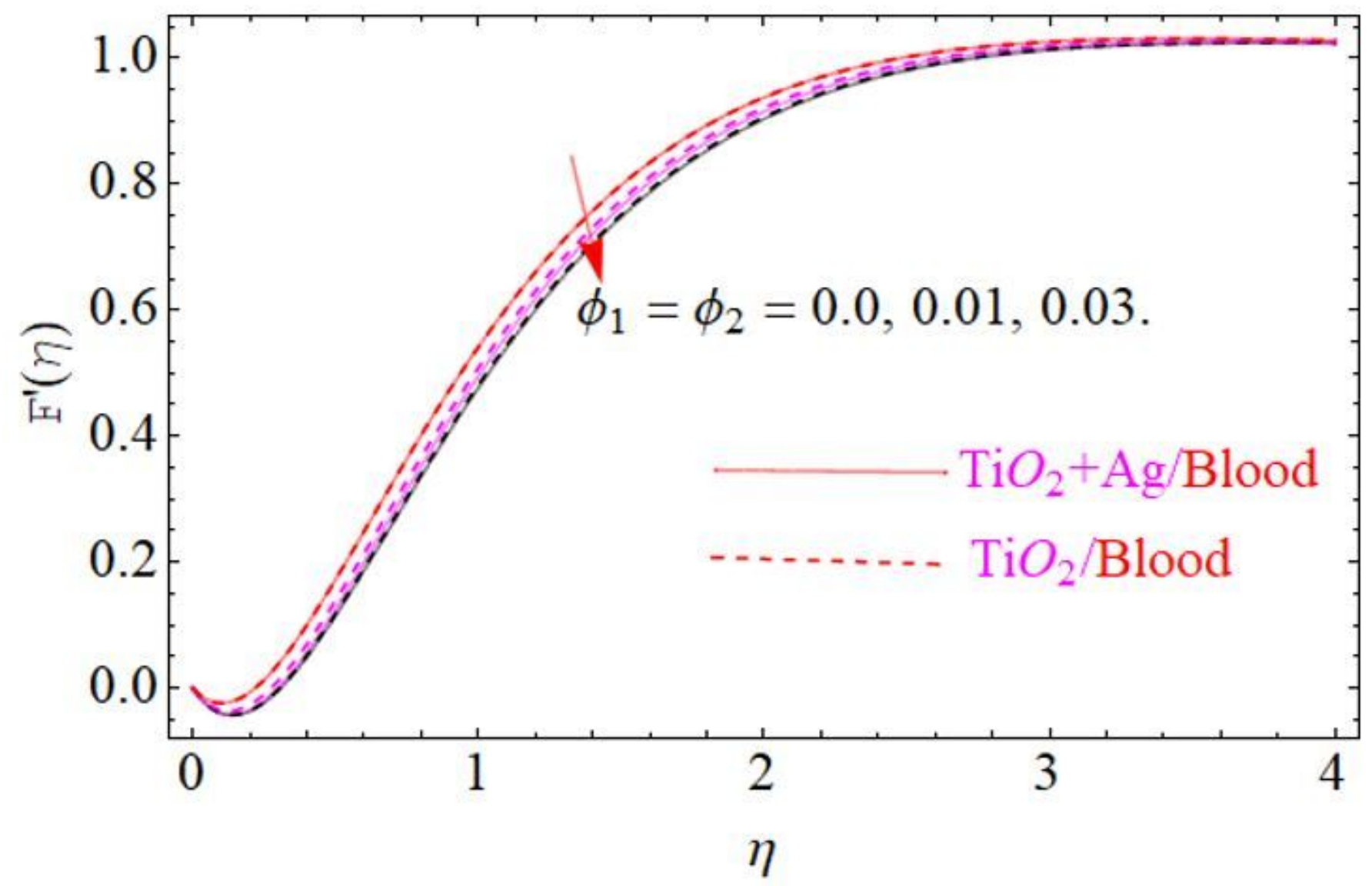

Figure 3

"See the Supplemental Files section for the complete figure caption". 


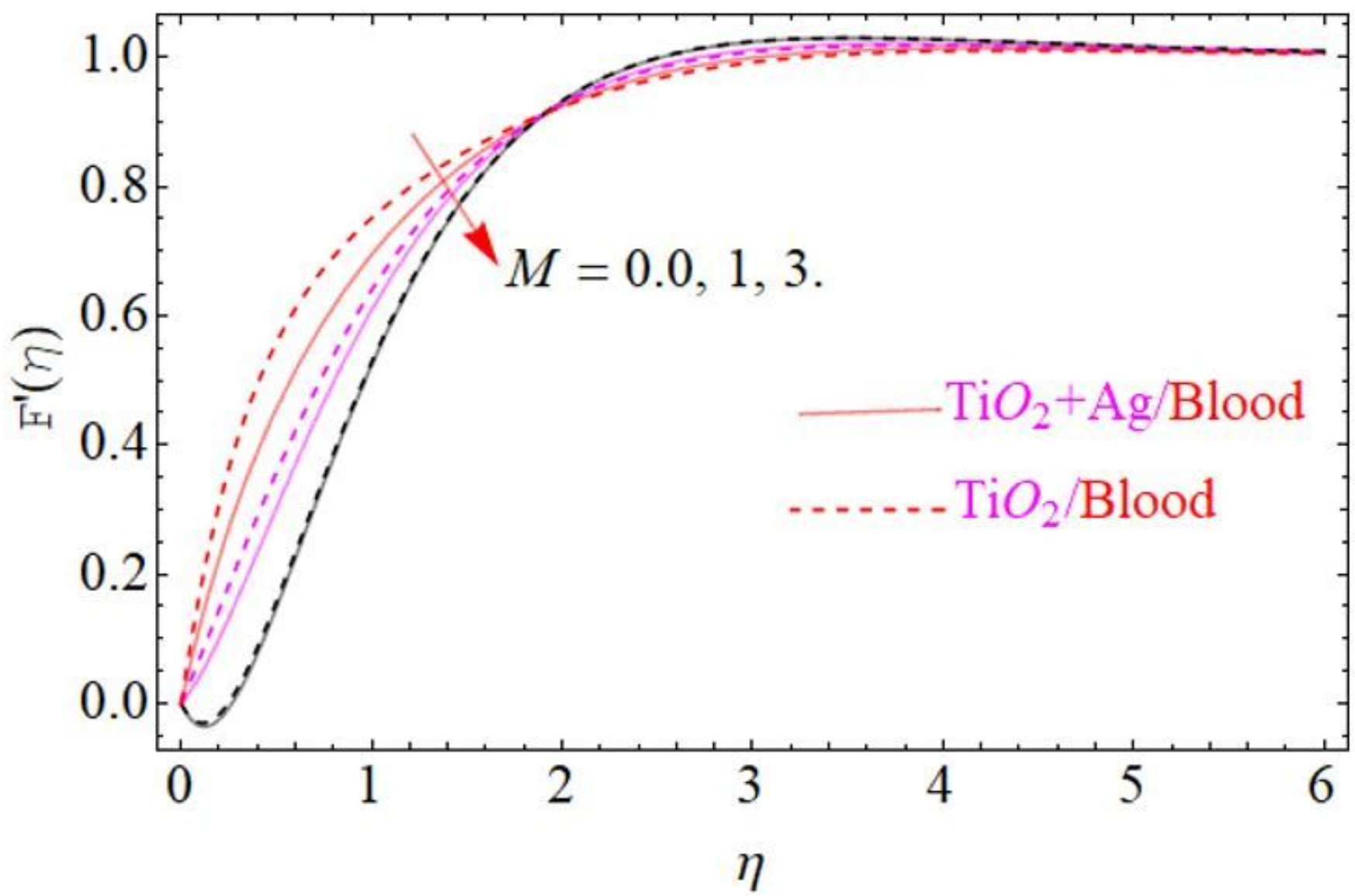

Figure 4

"See the Supplemental Files section for the complete figure caption". 


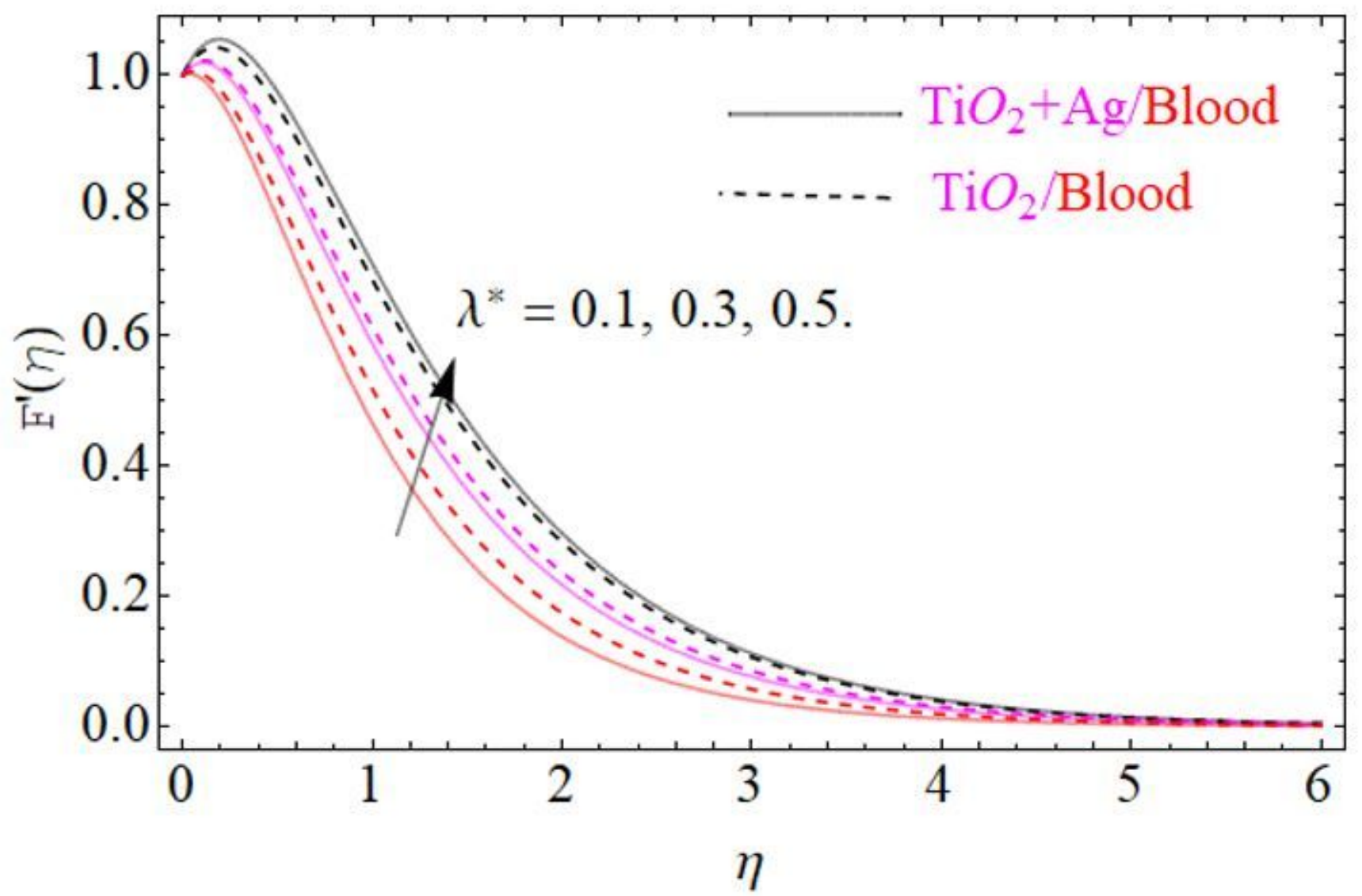

Figure 5

"See the Supplemental Files section for the complete figure caption". 


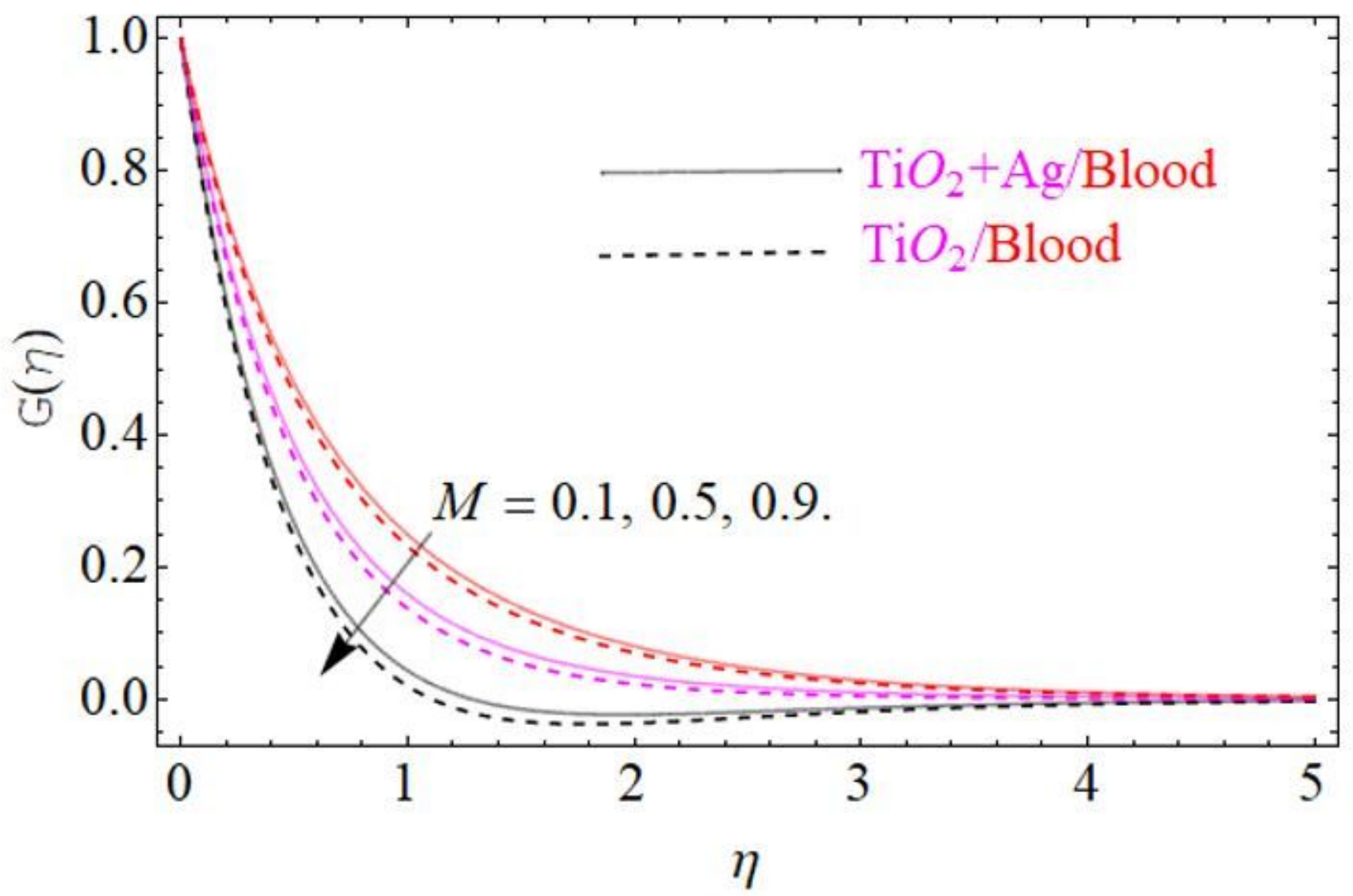

Figure 6

"See the Supplemental Files section for the complete figure caption". 


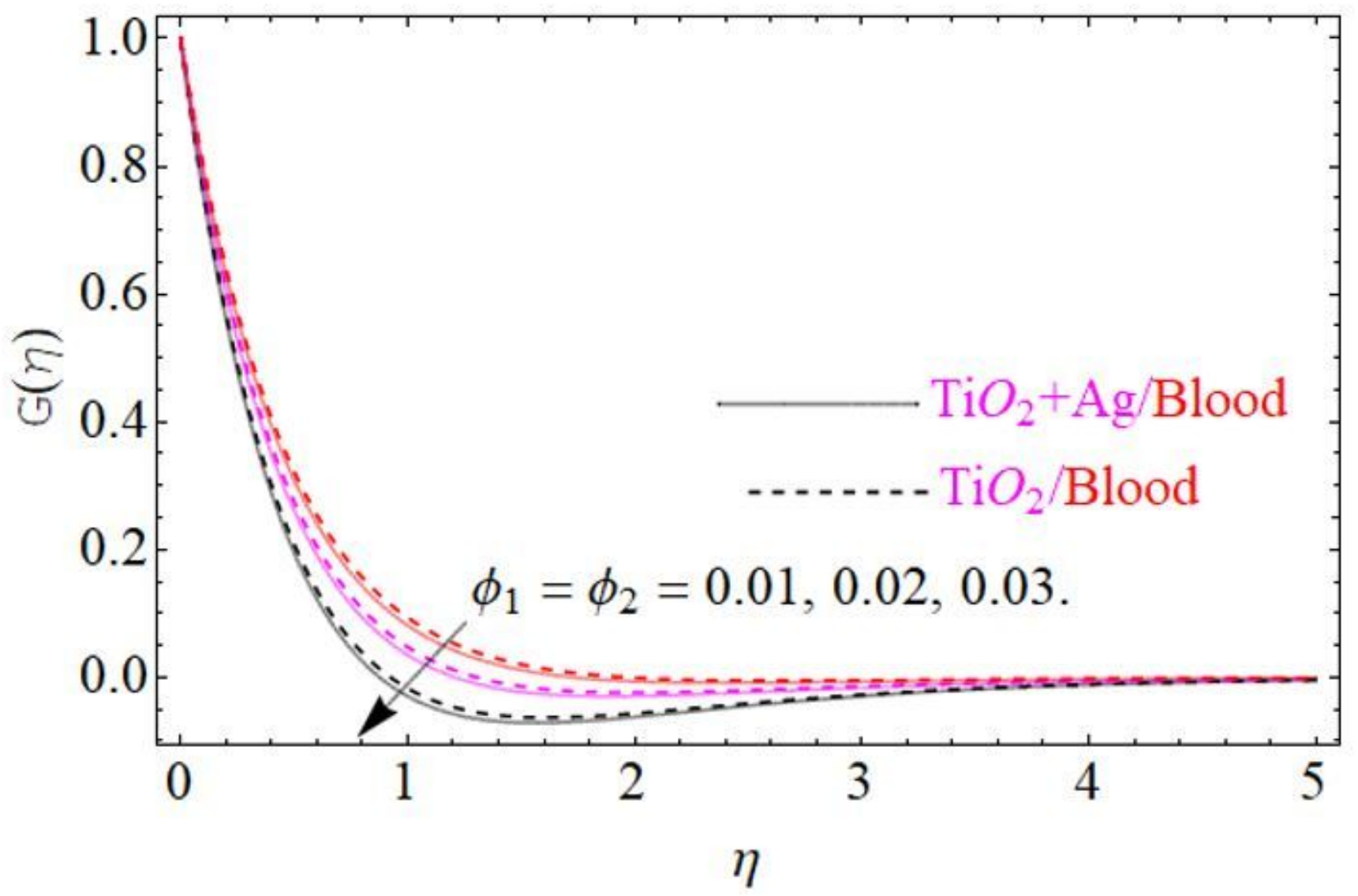

Figure 7

"See the Supplemental Files section for the complete figure caption". 


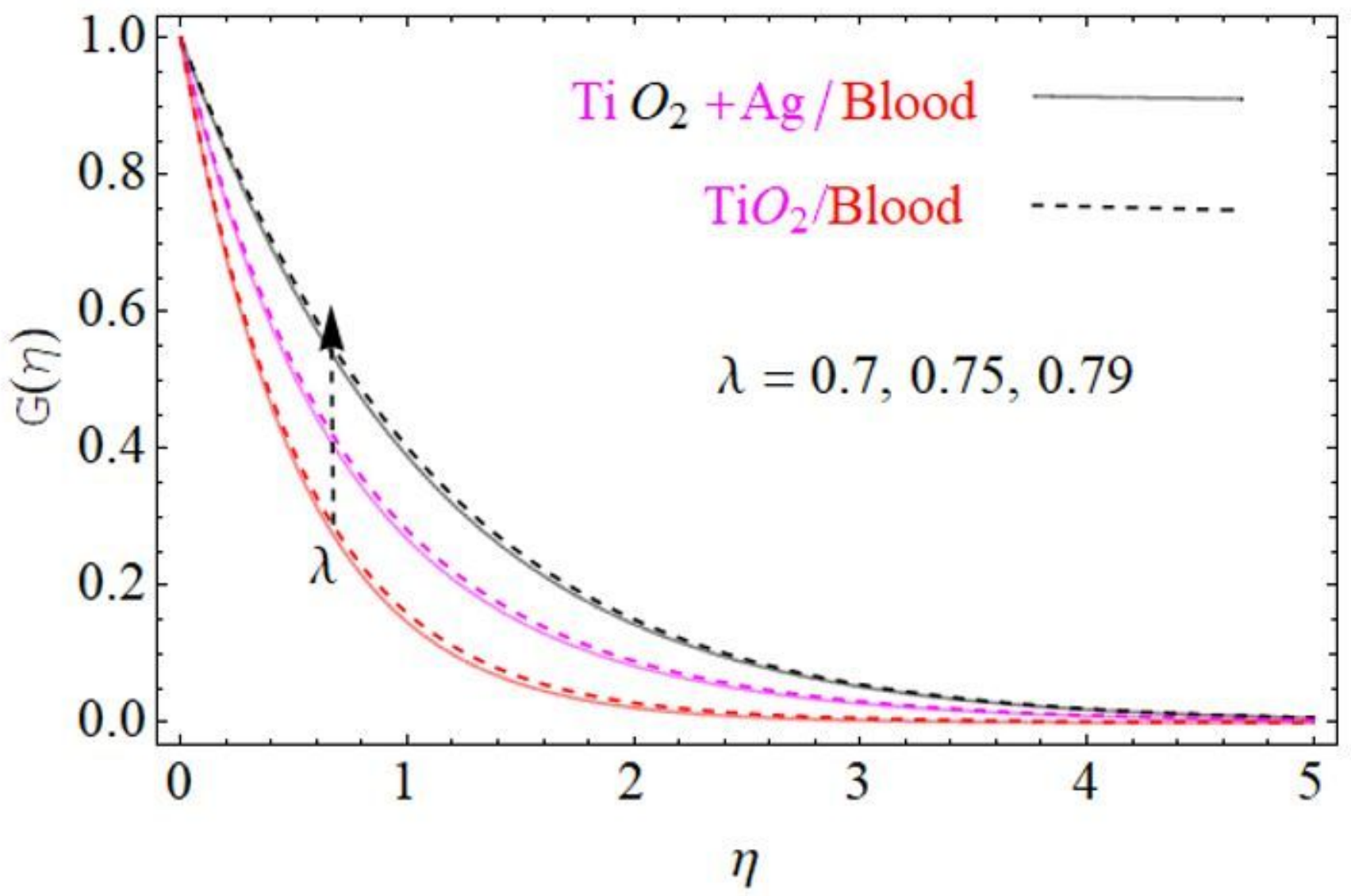

Figure 8

"See the Supplemental Files section for the complete figure caption". 


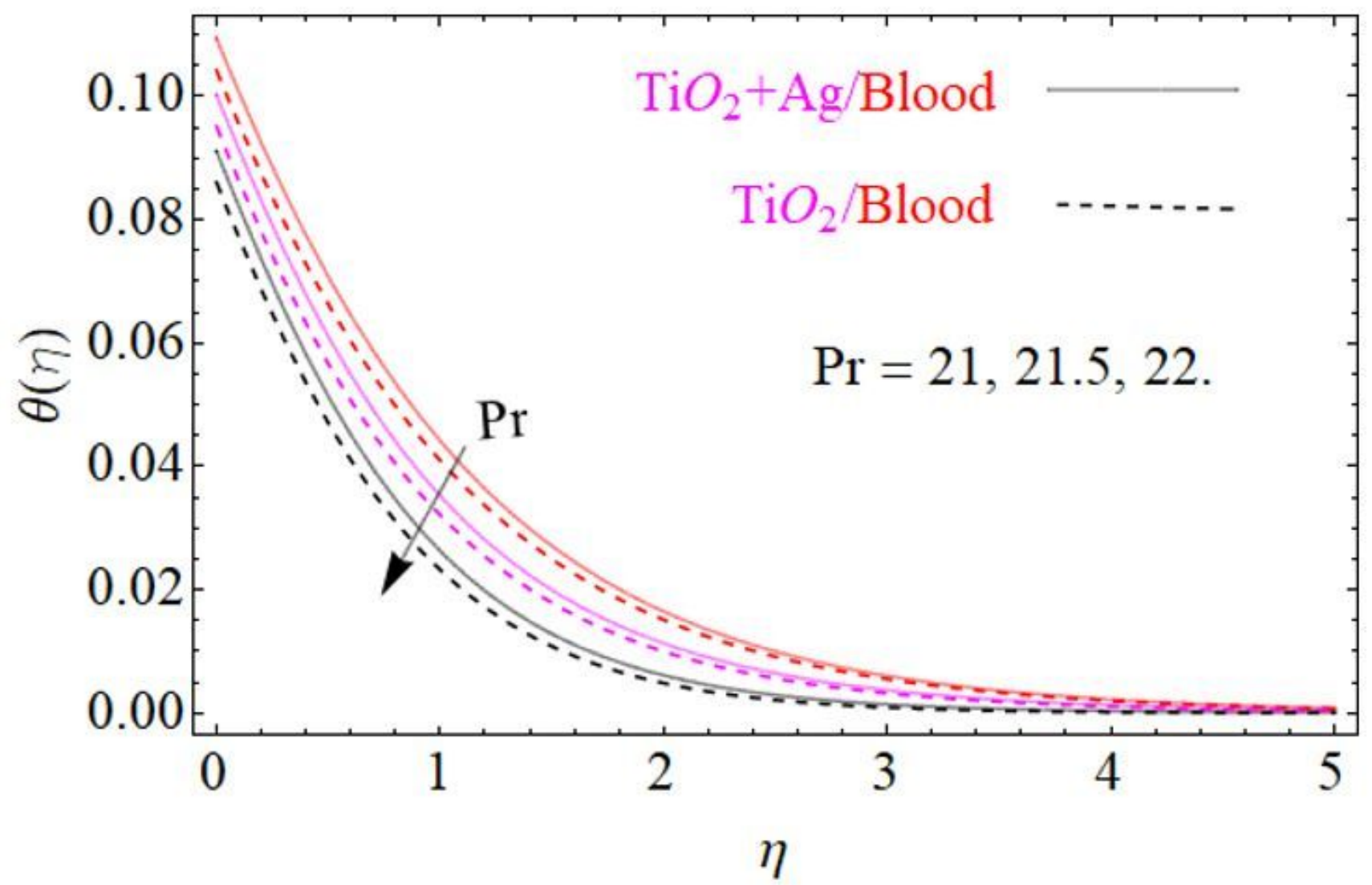

Figure 9

"See the Supplemental Files section for the complete figure caption". 


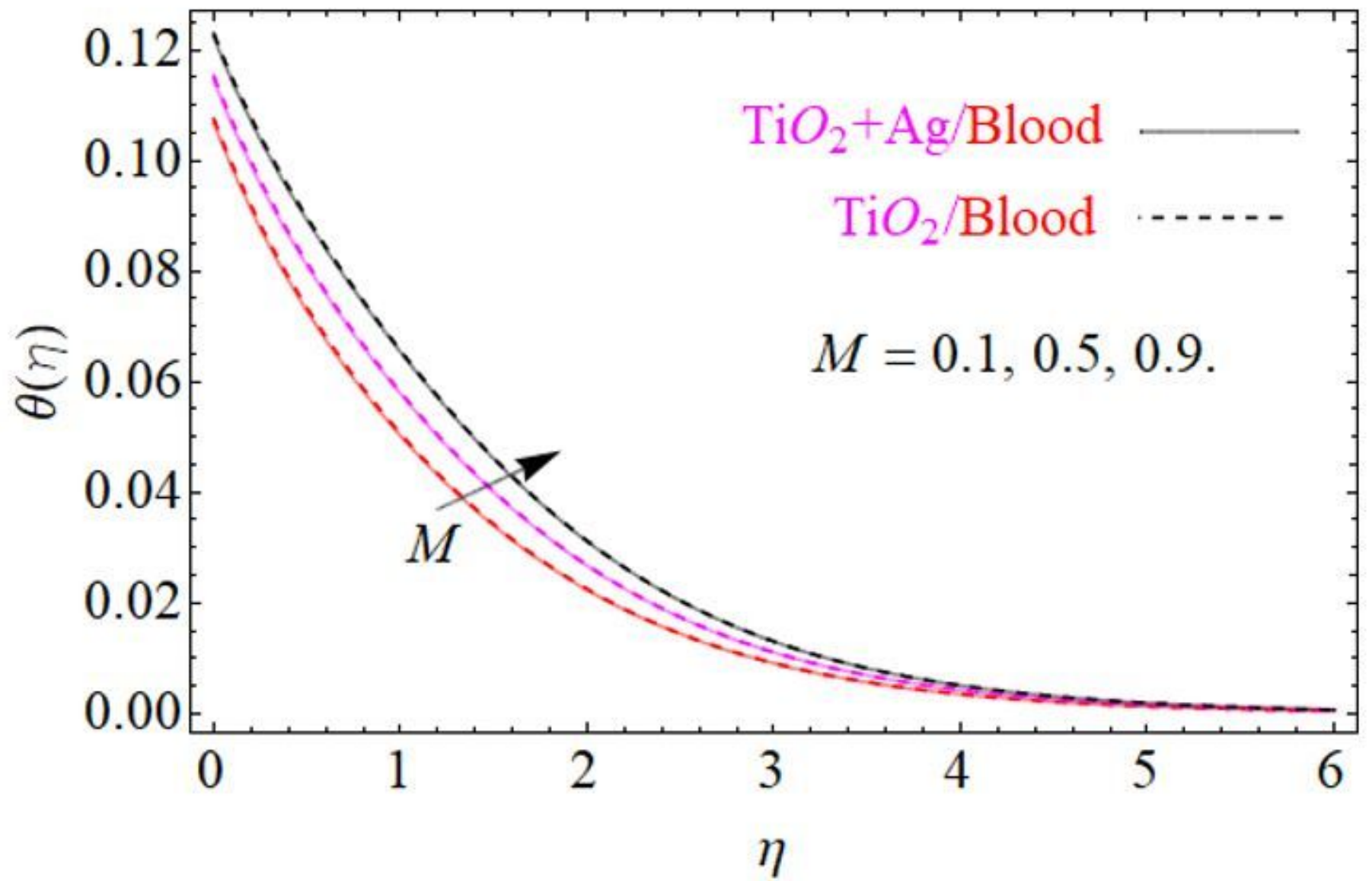

Figure 10

"See the Supplemental Files section for the complete figure caption". 


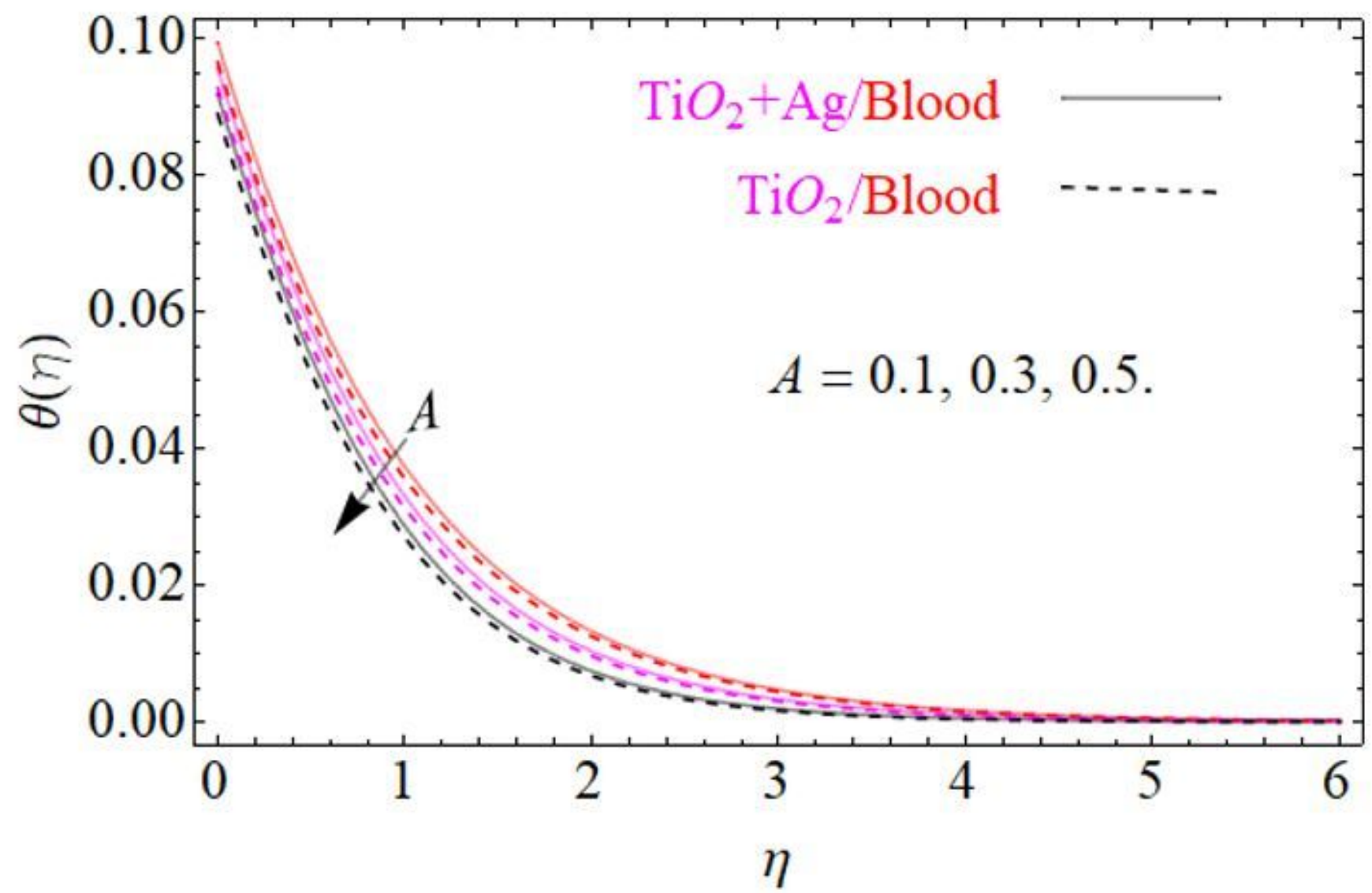

Figure 11

"See the Supplemental Files section for the complete figure caption". 


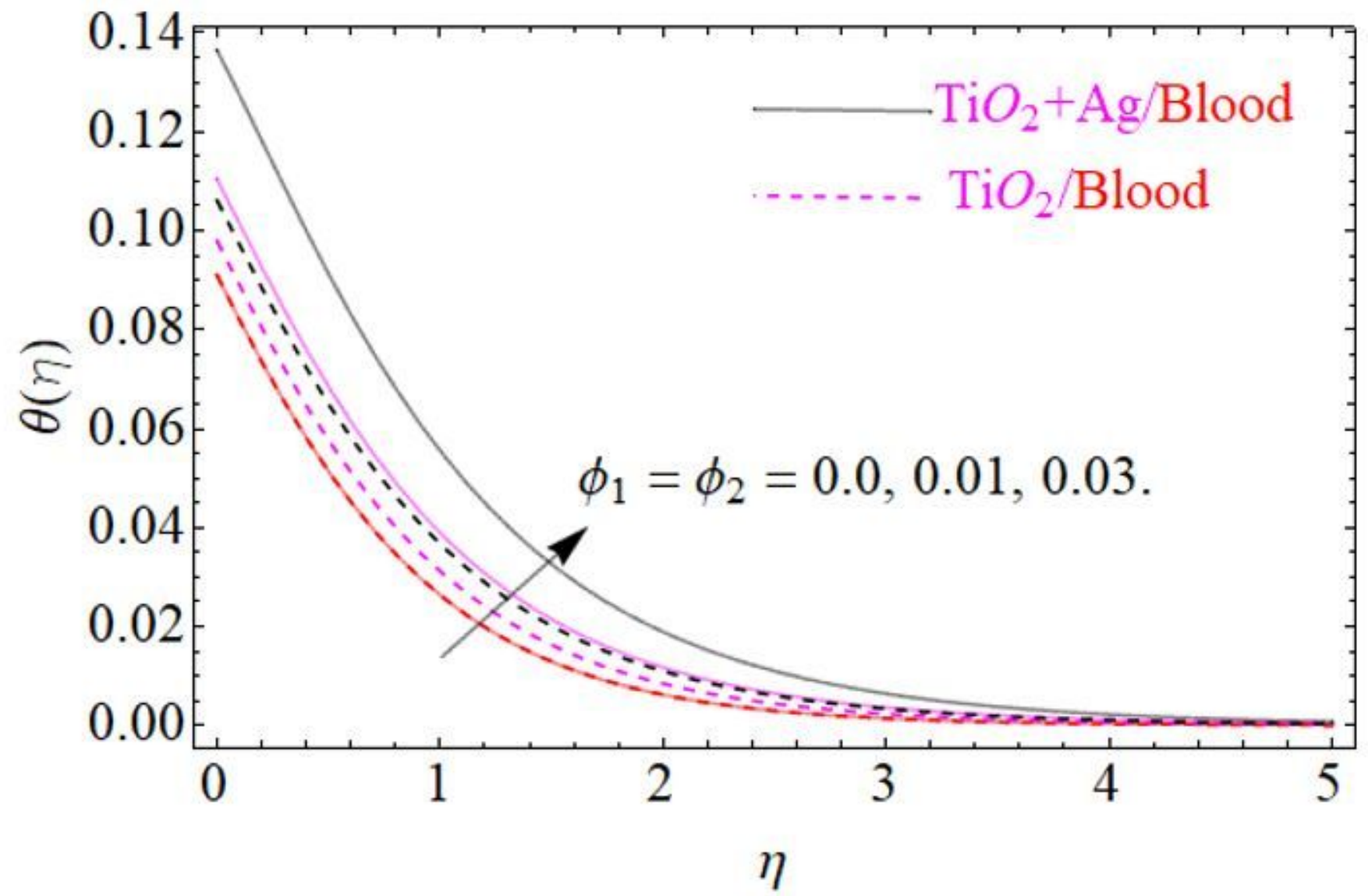

Figure 12

"See the Supplemental Files section for the complete figure caption". 


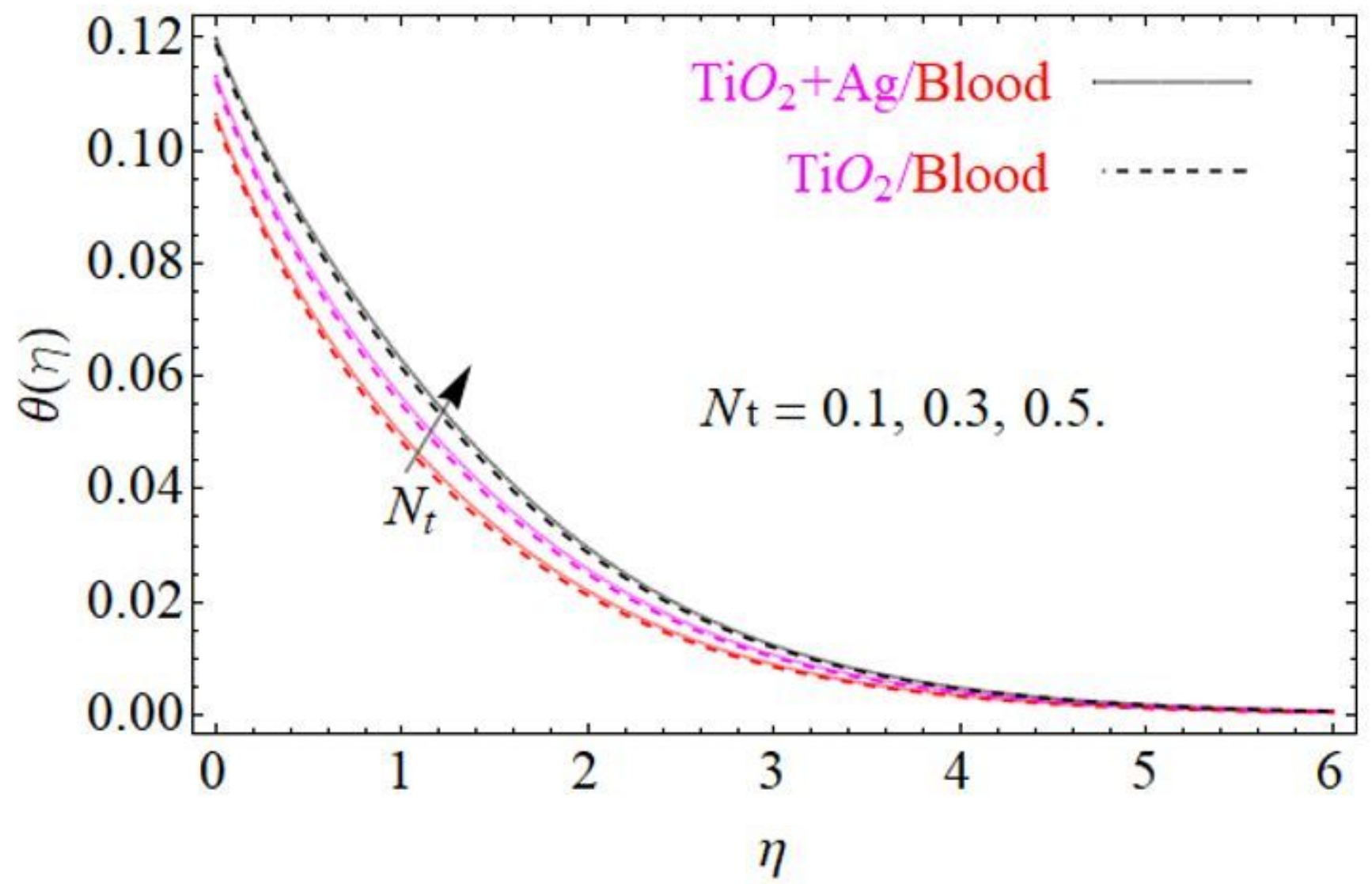

Figure 13

"See the Supplemental Files section for the complete figure caption". 


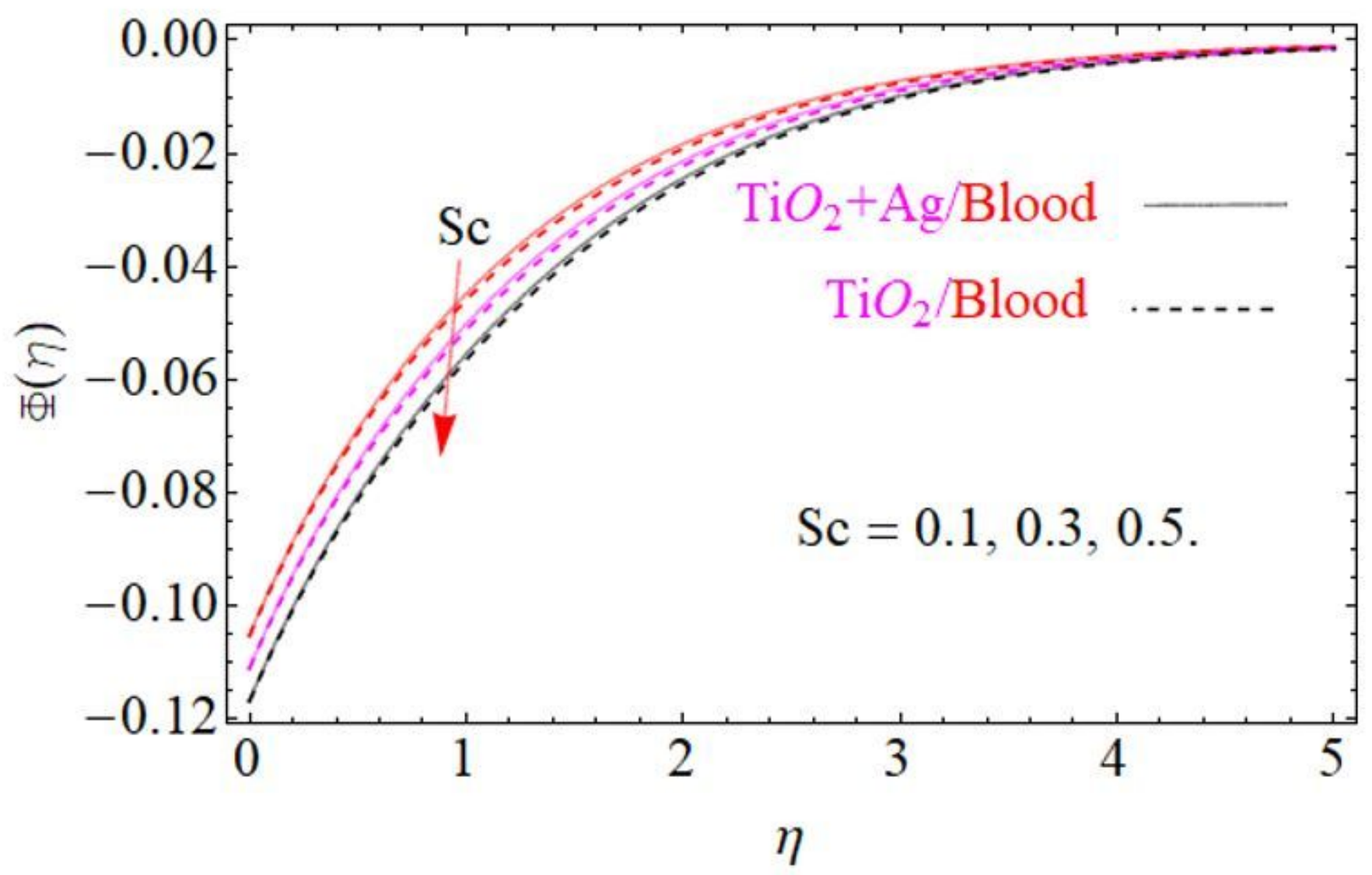

Figure 14

"See the Supplemental Files section for the complete figure caption". 


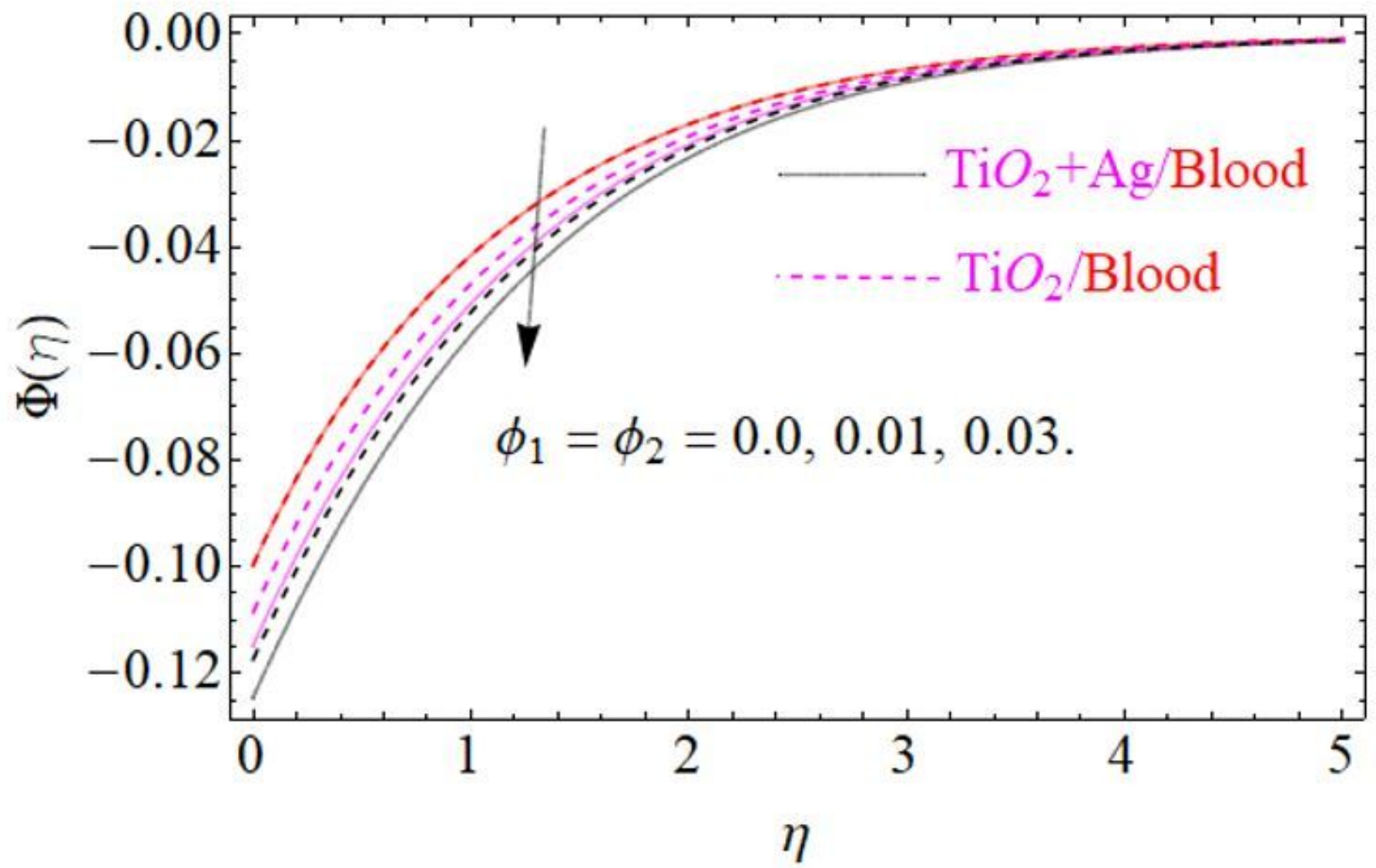

Figure 15

"See the Supplemental Files section for the complete figure caption". 


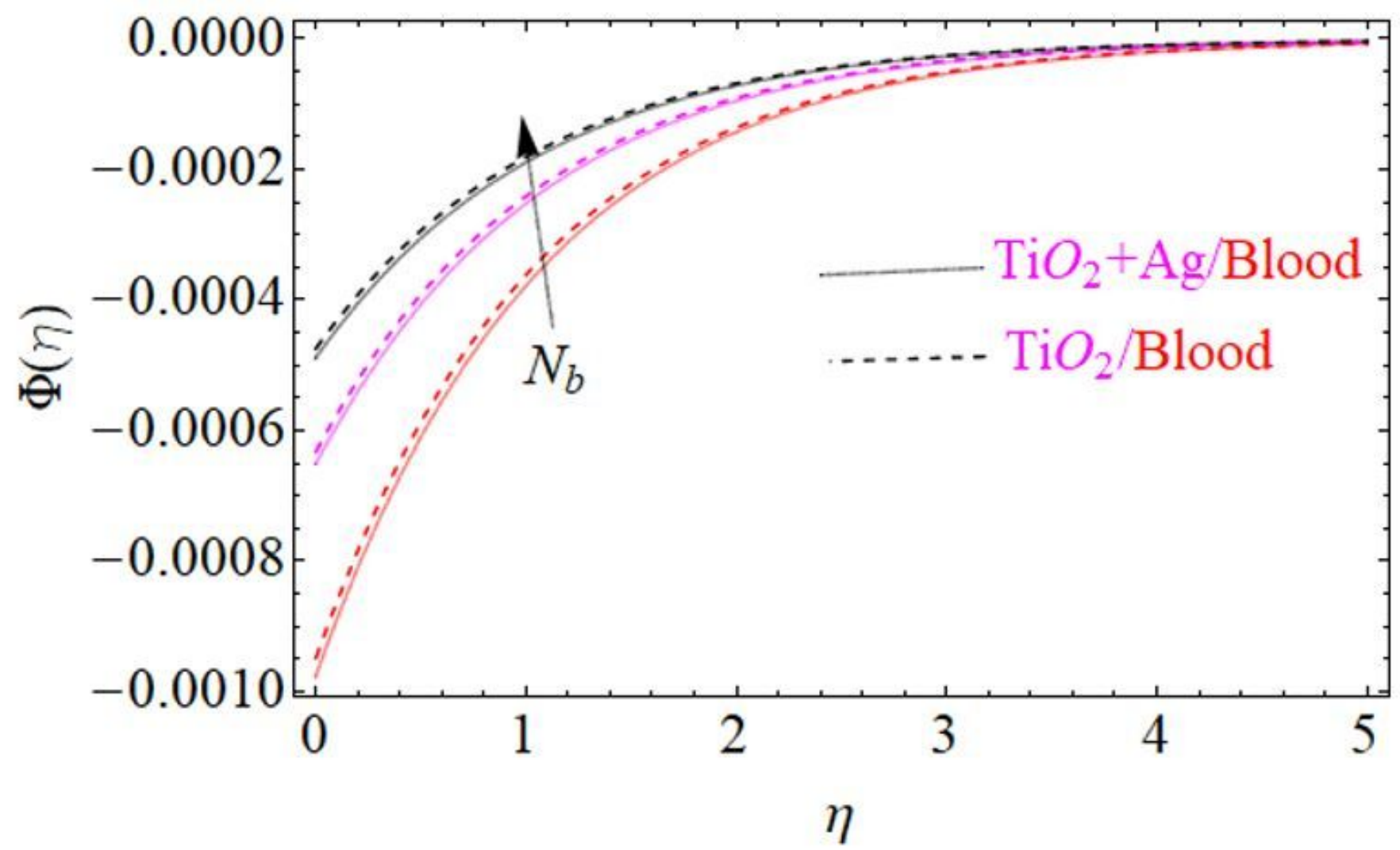

Figure 16

"See the Supplemental Files section for the complete figure caption".

\section{Supplementary Files}

This is a list of supplementary files associated with this preprint. Click to download.

- FigureCaptions.docx

- Tables.docx 